\title{
A new species of Oligodon Fitzinger, 1826 from the Langbian Plateau, southern Vietnam, with additional information on Oligodon annamensis Leviton, 1953 (Squamata: Colubridae)
}

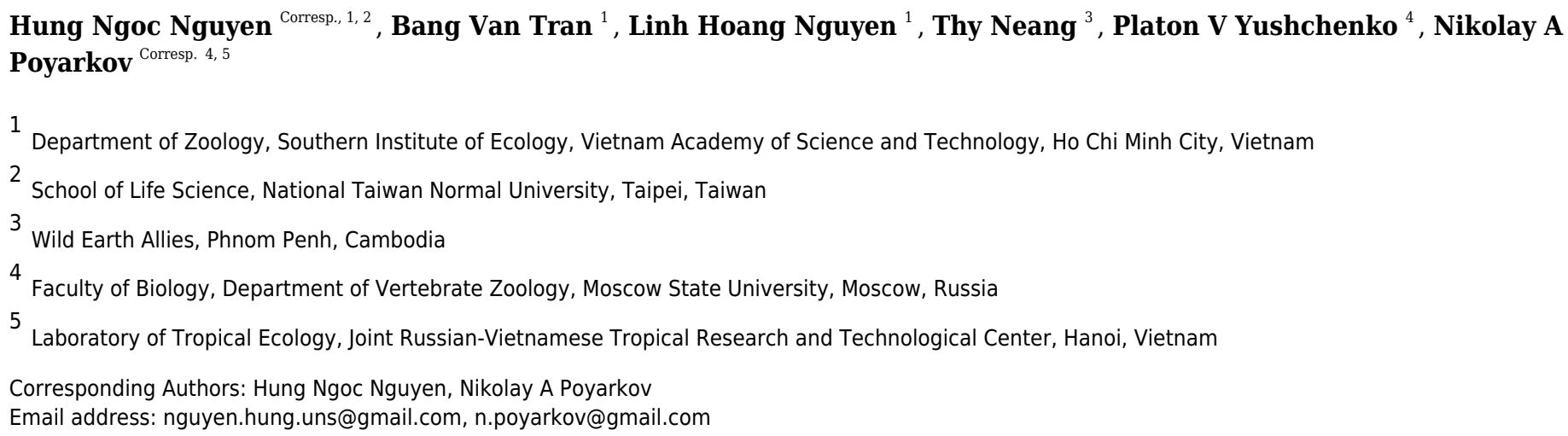

We describe a new species of Oligodon from the highlands of the Langbian Plateau, southern Truong Son Mountains, Vietnam, based on morphological and molecular phylogenetic analyses. The new species, Oligodon rostralis sp. nov. is distinguished from its congeners by the following morphological characters: medium size in adults (male $T L=$ $582 \mathrm{~mm}$ ); small and broad head with long protruding snout; dorsal scale row formula 15-15-13; 167 ventrals, 47 subcaudals; single preocular, single postocular; loreal and presubocular absent; six supralabials, third and fourth entering orbit; six infralabials, anterior four contacting first pair of chin shields; internasals separate from prefrontals; nasal divided; single anterior and two posterior temporals; cloacal plate undivided; hemipenes short, bilobed, bifurcating in anterior one third of their length, extending to 8th subcaudal, lacking spines and papillae, with a prominent transverse flounces and distal calyces; six maxillary teeth, the posterior three enlarged; dorsal pattern consisting of $14+4$ large dark-brown blotches and a bright-orange vertebral stripe on tail and dorsum; and ventral surfaces in life cream laterally with dark quadrangular spots; dark temporal streak present, edged with white. We also provide additional information on $O$. annamensis, including a morphological dataset of all specimens known from natural history collections and confirmation of an earlier record of $O$. annamensis from Cambodia. We also provide the first record of $O$. annamensis for Dak Lak Province. Phylogenetic analyses of mtDNA genes (3131 bp of 12S rRNA, 16S rRNA and cyt $b$ ) suggest sister relationships of Oligodon rostralis sp. nov. and $O$. annamensis and place them in one clade with the $O$. cyclurus and $O$. taeniatus species groups, which is concordant with previous studies on the phylogenetic relationships of Oligodon. Our study demonstrates Peer) reviewing PDF | (2019:10:41846:1:1:NEW 23 Nov 2019) 
high level of herpetofaunal diversity and endemism of Langbian Plateau and further supports the importance of this area for conservation herpetofaunal diversity in Indochina. 
1 TITLE:

2 A new species of Oligodon Fitzinger, 1826 from the Langbian Plateau,

3 southern Vietnam, with additional information on Oligodon annamensis

4 Leviton, 1953 (Squamata: Colubridae)

5

6 Hung Ngoc Nguyen",2*, Bang Van Tran', Linh Hoang Nguyen, Thy Neang, Platon V.

7 Yushchenko ${ }^{4}$, Nikolay A. Poyarkov ${ }^{4,5 *}$

$8{ }^{1}$ Department of Zoology, Southern Institute of Ecology, Vietnam Academy of Science and

9 Technology, Ho Chi Minh City, VIETNAM

$10{ }^{2}$ School of Life Science, National Taiwan Normal University, Taipei, TAIWAN

$11{ }^{3}$ Wild Earth Allies, Phnom Penh, CAMBODIA

$12{ }^{4}$ Faculty of Biology, Department of Vertebrate Zoology, Moscow State University, Moscow,

13 RUSSIA

145 Laboratory of Tropical Ecology, Joint Russian-Vietnamese Tropical Research and 15 Technological Center, Hanoi, VIETNAM

16 *corresponding authors: nguyen.hung.uns@gmail.com;n.poyarkov@gmail.com

RUNNING TITLE: New Oligodon from southern Vietnam

\section{ABSTRACT}

21 We describe a new species of Oligodon from the highlands of the Langbian Plateau, southern

22 Truong Son Mountains, Vietnam, based on morphological and molecular phylogenetic analyses.

23 The new species, Oligodon rostralis sp. nov. is distinguished from its congeners by the 
24 following morphological characters: medium size in adults (male TL $=582 \mathrm{~mm}$ ); small and 25 broad head with long protruding snout; dorsal scale row formula 15-15-13; 167 ventrals, 47

26 subcaudals; single preocular, single postocular; loreal and presubocular absent; six supralabials,

27 third and fourth entering orbit; six infralabials, anterior four contacting first pair of chin shields;

28 internasals separate from prefrontals; nasal divided; single anterior and two posterior temporals; cloacal plate undivided; hemipenes short, bilobed, bifurcating in anterior one third of their length, extending to 8th subcaudal, lacking spines and papillae, with a prominent transverse flounces and distal calyces; six maxillary teeth, the posterior three enlarged; dorsal pattern consisting of 14+4 large dark-brown blotches and a bright-orange vertebral stripe on tail and dorsum; and ventral surfaces in life cream laterally with dark quadrangular spots; dark temporal streak present, edged with white. We also provide additional information on O. annamensis, including a morphological dataset of all specimens known from natural history collections and confirmation of an earlier record of $O$. annamensis from Cambodia. We also provide the first record of O. annamensis for Dak Lak Province. Phylogenetic analyses of mtDNA genes (3131 bp of 12S rRNA, 16S rRNA and cyt $b$ ) suggest sister relationships of Oligodon rostralis sp. nov. and $O$. annamensis and place them in one clade with the $O$. cyclurus and $O$. taeniatus species groups, which is concordant with previous studies on the phylogenetic relationships of Oligodon. Our study demonstrates high level of herpetofaunal diversity and endemism of Langbian Plateau and further supports the importance of this area for conservation herpetofaunal diversity in Indochina.

SUBJECTS: Biodiversity, Zoology 
47 KEYWORDS: Oligodon rostralis sp. nov., Cambodia, Truong Son Mountains, Annamites, endemism, hemipenis morphology, taxonomy, distribution, morphology, mtDNA

\section{INTRODUCTION} known as a local center for herpetofaunal endemism. It is inhabited by numerous species of amphibians and reptiles, many of which were only described recently (Duong et al., 2018; Nazarov et al., 2012; Poyarkov et al., 2014, 2015a, 2015b, 2017, 2019b; Stuart et al., 2011; Rowley et al., 2016; Vassilieva et al., 2014). The Kukri Snakes of the genus Oligodon Fitzinger, 1826, are one of the most speciose and taxonomically problematic colubrid snake groups distributed in South and Southeast Asia, with over 79 species described (Green et al., 2010; Wallach et al., 2014; Uetz et al., 2019). Due to their secretive behavior (Tillack \& Günther, 2009), many species are known from only a few specimens or even only the holotype. Consequently, knowledge regarding Oligodon taxonomy, distribution, morphological variation and natural history is limited (Leviton 1953, 1960; Pauwels et al., 2002; David et al., 2008; Neang et al., 2012). In Vietnam 23 species of Oligodon have been recorded up to date, with six of them being country endemic, while eight species were described within the last decade (David et al., 2008, 2012; Nguyen et al., 2016, 2017; Vassilieva et al., 2013; Vassilieva, 2015). This suggests that our knowledge of Oligodon diversity in the Indochinese region is still far from complete. annamensis Leviton, 1953, which was described based on a single female specimen collected from "Blao, Haut Donai" in the Langbian plateau (currently Bao Loc, Lam Dong Province, south 
70

71

Vietnam) (Leviton, 1953, 1960). Leviton (1953) was puzzled by the taxonomic and phylogenetic affinities of this species, and only after examining a second male specimen he assumed that $O$. annamensis might be a part of the "taeniatus-cyclurus-complex" (Leviton, 1960). The only other existing record of this species was recently published by Neang \& Hun (2013), who reported a subadult specimen identified as Oligodon annamensis from Phnom Samkos Wildlife Sanctuary of the Cardamom Mountains in southwest Cambodia; over $600 \mathrm{~km}$ westwards from the type locality (Neang \& Hun, 2013). However, identification of the Cambodian specimen was tentative and has not been confirmed by molecular analyses; no information on the phylogenetic position of $O$. annamensis is available until this paper.

During our recent surveys in Lam Dong and Dak Lak provinces of southern Vietnam we collected two Oligodon specimens superficially similar in morphology with description of $O$. annamensis. However, after a closer examination of specimens from Vietnam and Cambodia, comparison of diagnostic morphological traits and phylogenetic analyses of $3131 \mathrm{bp}$ of mtDNA, we were able to identify the Dak Lak and Cambodian specimens as $O$. annamensis, while the Oligodon specimen from Lam Dong Province showed a unique combination of morphological characters that differ it significantly from all other Oligodon taxa. Furthermore, the phylogenetic analyses of mtDNA markers suggest that the Lam Dong Oligodon sp. represents a distinct phylogenetic lineage, not conspecific to any other Oligodon sequences available. Herein it is assigned to a new species, which is described below.

MATERIALS AND METHODS

Nomenclatural acts 

published work according to the International Commission on Zoological Nomenclature (ICZN),

94 and hence the new names contained in the electronic version are effectively published under that Code from the electronic edition alone (see Articles 8.5-8.6 of the Code). This published work and the nomenclatural acts it contains have been registered in ZooBank, the online registration system for the ICZN. The ZooBank LSIDs (Life Science Identifiers) can be resolved and the associated information can be viewed through any standard web browser by appending the LSID to the prefix http://zoobank.org/. The LSID for this publication is as follows: urn:1sid:zoobank.org:pub:51B851C2-5D34-4065-86EA-CF18DDD94419. The online version of this work is archived and available from the following digital repositories: PeerJ, PubMed Central and CLOCKSS.

Sampling. The adult male specimen of Oligodon sp. was collected by Bang Van Tran and Linh Hoang Nguyen during the field trip in June 2017 in Bidoup - Nui Ba National Park (hereafter NP), Lam Dong Province, Vietnam (locality 1; Figure 1). After euthanasia with 20\% solution of benzocaine, the specimen was initially preserved in $95 \%$ alcohol for one day then subsequently stored in $70 \%$ alcohol. Additional specimens of Oligodon annamensis were collected in Chu Yang Sin NP, Dak Lak Province, southern Vietnam, by Nikolay A. Poyarkov (locality 3; Figure 1); and in Phnom Samkos Wildlife Sanctuary (hereafter WS) of the Cardamom Mountains, Pursat Province, southwest Cambodia by Seiha Hun (locality 4; Figure 1); both records made in April, 2012. Geographic position of the surveyed localities is shown in Figure 1. Because of certain morphological similarity with Oligodon annamensis in coloration and scalation (Orlov et al., 2010), we also included sequences of O. lacroixi in our phylogenetic analysis based on a specimen from Phu Tho Province, northern Vietnam. 
116 Committee of Southern Institute of Ecology, Vietnamese Academy of Science and Technology

117 (certificate number 114/QD-STHMN of November 8, 2016).

118 Field work, including collection of samples and animals in the field, was authorized the

119 Bureau of Forestry, Ministry of Agriculture and Rural Development of Vietnam (permits Nos.

$120170 /$ TCLN-BTTN of $07 / 02 / 2013 ; 400 /$ TCLN-BTTN of 26/03/2014; 831/TCLN-BTTN of

121 05/07/2013) and Forest Protection Department of the Peoples' Committee of Dak Lak Province

122 (permit No. 388/SNgV-LS of 24/04/2019); the fieldwork in Bidoup - Nui Ba NP was conducted

123 under scope of the contract between Sustainable Nature Resource Management Project (SNRM)

124 under Japan International Cooperation Agency and Southern Institute of Ecology to perform the

125 "Biodiversity Baseline Survey" project of September 24, 2018.

126

Morphological analysis. Color characters and patterns were recorded during examination of specimens in life and taken from digital images of the living specimens.

Morphological characters and morphometric ratios considered to be of taxonomic importance for

Oligodon were used for species descriptions and followed a number of recent revisions of the genus (David et al., 2008; 2012; Leviton, 1953, 1960; Neang \& Hun, 2013; Nguyen et al., 2016, 2017; Vassilieva et al., 2013; Vassilieva, 2015). All body measurements, except body and tail lengths, were taken under a binocular microscope using digital slide-caliper to the nearest 0.1 $\mathrm{mm}$. Body and tail lengths were measured to the nearest millimetre with a measuring tape. The

134 right hemipenis was forcedly everted by using water injection prior the preservation of the 135 specimen. Methodology of ventral and subcaudal scales counts followed Dowling (1951). 136 Terminology for hemipenial structures generally followed Smith (1943) and Dowling \& Savage 
137 (1960). Maxillary teeth of the specimens were counted by examining both maxillae, directly by

138 pushing back the soft tissue with a needle under binocular microscope prior to preservation.

The following measurements (all in $\mathrm{mm}$ ) and counts were taken: snout to vent length

140 (SVL) - measured from the tip of the snout to the vent; tail length (TaL) - measured from the

141 vent to the tip of the tail; total length (TL) - sum of SVL and TaL; relative tail length to total

142 length (RTL) calculated as tail length to total length ratio (TaL/TL); head length (HL) from the

143 tip of the snout to the posterior margin of the mandible; head width (HW) measured at the widest

144 part of the head immediately posterior to the eye; head width to head length ratio (HW/HL);

145 snout length $(\mathrm{SnL})$ — distance between the tip of the snout and anterior edge of eye; eye

146 diameter (EyeL) - maximal horizontal length of the eye; frontal scale length/width (FrL/FrW)

147 - length and width of the frontal scale; interorbital distance (IOD) — the shortest distance

148 between the eyes; internarial distance (IND) — distance between the nostrils; number of

149 maxillary teeth (DEN); dorsal scale rows at neck (ASR) - number of scale rows at one head

150 length behind the head; midbody scale rows (MSR) — number of scale rows at midbody; dorsal

151 scale rows anterior to the vent (PSR) - number of dorsal scale rows at one head length prior to

152 the vent; dorsal scale rows formula (DSR) — referred to as a general scale formula in the form

153 "ASR-MSR-PSR" (for number of dorsal scale rows at neck, midbody and prior to vent,

154 respectively); first dorsal scale reduction (RED1) - the first reduction of dorsal scale rows,

155 corresponding to a ventral scale; ventral scales (VS) - number of scales from the second ventral

156 scale posterior to gulars to the vent excluding cloacal plate; cloacal plate (AP) - number of

157 terminal ventral scales immediately anterior to vent; subcaudal scales (SC) — number of paired

158 subcaudal scales excluding the terminal scute; total belly scales (Total Sc.) — sum of ventral and

159 subcaudal scales; supralabials (SL) - number of scales on upper lip; SL-Eye — number of SL 
160 entering orbit; infralabials (IL) - number of scales on lower lip; infralabials contacting each 161 other (IL-contact) - number of pairs of infralabial scales in contact; infralabials contacting the 162 anterior chin shields (IL-CS) - infralabial scales contacting the upper chin shields; number of 163 preocular scales (PrO); number of presubocular scales (PrsO); number of postocular scales 164 (PtO); number of anterior temporals (Ate) — temporal scales which contact the postocular 165 scales; number of posterior temporals (Pte) - temporal scales immediately contacting the 166 anterior temporal scales; condition of loreal scale (LOR) - 1 - present, 0 - absent, * - vestigial; 167 condition of nasal scale (NAS) - D - vertically divided, E - entire, PD - partially divided; 168 hemipenis shape - (1) unforked, a single organ with no lobes at apex; (2) bilobed, organ contains two lobes at its apex; hemipenis ornamentation — notes on ornamentation of organ (i.e.

170 spinules, calyces or flounces); presence of appendages seen in situ (papillae sensu Smith, 1943);

171 hemipenis length - length of the everted hemipenis in $\mathrm{mm}$ and relative to number of subcaudal 172 scales. Symmetric characters are given in left / right order. Other abbreviations: a.s.1.: above sea 173 level; Div.: Division; Comm.: Commune; Dist.: District; Mt.: mountain; NP: National Park; NR: 174 Nature Reserve; Prov.: Province; WS: Wildlife Sanctuary.

175 The type material was deposited in the herpetological collection of the Department of Zoology, 176 Southern Institute of Ecology (SIEZC) in Ho Chi Minh City, Vietnam. Additional material used 177 for comparisons is stored in the herpetological collections of Centre for Biodiversity 178 Conservation of the Royal University of Phnom Penh, Phnom Penh, Cambodia (CBC RUPP); 179 United States National Museum, Washington, D. C., USA (USNM); Museum National d'Histoire 180 Naturelle, Paris, France (MNHN) and Zoological Museum of Lomonosov Moscow State 181 University, Moscow, Russia (ZMMU). 

95\% ethanol using the Qiagen DNAeasy Blood \& Tissue Kit following manufacturers' protocol.

We used the polymerase chain reaction (PCR) to amplify two fragments of mitochondrial DNA (hereafter mtDNA): the first fragment including partial sequences of $12 \mathrm{~S}$ ribosomal RNA (rRNA), tRNA-Valine and 16 rRNA genes (total length up to $2035 \mathrm{bp}$ ) and a complete sequence of cytochrome $b$ gene (1096 bp). Primers used for both PCR and sequencing are summarized in Table 1.

PCR protocol for 12S-16S rRNA mtDNA fragment in general followed Green et al. initial denaturation step at $94^{\circ} \mathrm{C}$ for 5 min; (2) 35 cycles of denaturation at $94^{\circ} \mathrm{C}$ for 1 min, annealing at $55^{\circ} \mathrm{C}$ for $1 \mathrm{~min}$ and extension at $72^{\circ} \mathrm{C}$ for $1 \mathrm{~min}$; (3) final extension at $72^{\circ} \mathrm{C}$ for 10 min; and (4) cooling step at $4^{\circ} \mathrm{C}$ for storage.

For cytochrome $b$ sequences (fragment up to $1096 \mathrm{bp}$ ) we used a modified PCR protocol cycles of denaturation at $94^{\circ} \mathrm{C}$ for $1 \mathrm{~min}$, annealing for 1 min with temperature decreasing from $50^{\circ} \mathrm{C}$ to $45^{\circ} \mathrm{C}$ (with cool-down at $0.5^{\circ} \mathrm{C}$ per each cycle) and extension at $72^{\circ} \mathrm{C}$ for $1 \mathrm{~min}$; (3) 24 cycles of denaturation at $94^{\circ} \mathrm{C}$ for $1 \mathrm{~min}$, annealing at $45^{\circ} \mathrm{C}$ for $1 \mathrm{~min}$ and extension at $72^{\circ} \mathrm{C}$ for 1 min; (4) final extension at $72^{\circ} \mathrm{C}$ for $10 \mathrm{~min}$; and (5) cooling step at $4^{\circ} \mathrm{C}$ for storage.

All PCR products were sequenced in both directions by Genomics BioSci \& Tech Corp. 201 (Taipei, Taiwan). Sequences were assembled and checked using sequencher 4.9 (GeneCodes). MN395604 and MN396762-MN396765 (Table 2). 
Phylogenetic analyses. The 12S-16S rRNA datasets of Green et al. (2010), Pyron et al.

205

206

207

208

209

210

211

212

213

214

215

216

217

218

219

220

221

222

223

224

225

(2013), our newly obtained sequences and other Oligodon sequences available in GenBank were used to examine the position of the Lam Dong Oligodon sp. in the matrilineal genealogy of the genus (summarized in Table 2). In total, we analysed mtDNA sequence data for 52 specimens, including 43 samples of ca. 24 species of Oligodon, and eight outgroup sequences of other Colubrinae representatives, and sequences of Hebius vibakari (Natricinae) which were used to root the tree.

Nucleotide sequences were initially aligned in MAFFT v.6 (Katoh et al., 2002) with default parameters, and subsequently checked by eye in BioEdit 7.0.5.2 (Hall, 1999) and slightly adjusted. MODELTEST v.3.6 (Posada \& Crandall, 1998) was applied to estimate optimal evolutionary models for the data set analysis. Mean uncorrected genetic distances ( $p$-distances) were calculated in MEGA 6.0 (Tamura et al., 2013).

The matrilineal genealogy was inferred using Bayesian inference (BI) and Maximum Likelihood (ML) approaches. The best-fitting model for both BI and ML analyses for 12S-16S rRNA fragments was the GTR $+\mathrm{G}+\mathrm{I}$ model as of DNA evolution suggested by the Akaike Information Criterion (AIC); for cyt $b$ gene AIC suggested GTR $+\mathrm{G}$ model for first and third codon partitions, and $\mathrm{HKY}+\mathrm{G}+\mathrm{I}$ for second codon partition. BI was conducted in MrBayes 3.1.2 (Ronquist \& Huelsenbeck, 2003); Metropolis-coupled Markov chain Monte Carlo (MCMCMC) analyses were performed run with one cold chain and three heated chains for twenty million generations and sampled every 2000 generations. Five independent MCMCMC run iterations were performed and 1000 trees were discarded as burn-in. The convergence of the runs were checked by exploring examining the likelihood plots in TRACER v1.6 (Rambaut et al., 2014); 
226 the effective sample sizes (ESS) were all above 200. Nodal support was assessed by calculating

227 posterior probabilities (BI PP).

228 ML was conducted using the RAxML web server (http://embnet.vital-it.ch/raxml-bb/;

229 Kozlov et al., 2018). Confidence in nodal topology was estimated by non-parametric

230 bootstrapping (ML BS) with 1000 pseudoreplicates (Felsenstein, 1985).

231 We a priori regarded tree nodes with BI PP values over 0.95 and ML BS values $75 \%$ or 232 greater as sufficiently resolved; while BI PP values between 0.95 and 0.90 and ML BS values 233 between $75 \%$ and $50 \%$ were regarded as tendencies. Lower values were regarded as indicating 234 unresolved nodes (Huelsenbeck \& Hillis, 1993).

235

236

\section{RESULTS}

237

\section{Phylogenetic relationships of Oligodon}

Sequence and statistics. The final concatenated alignment of the 12S rRNA - 16S rRNA conserved and 1049 sites were variable, of which 713 were found to be parsimony-informative. The transition-transversion bias (R) was estimated as 1.89 . Nucleotide frequencies were $38.0 \%$ (A), 22.0\% (T), 24.5\% (C), and 15.4\% (G) (all data given for ingroup only).

2) inferred the following set of phylogenetic relationships, which is generally consistent with the

247 (see Figure 2): 
248 (1) Clade 1: Indian and Sri Lankan species (O. taeniolatus, O. calamarius, O. sublineatus; 1.0/100; hereafter node support values are given for BI PP/ML BS, respectively); $O$. arnensis from the same region tends to group with this clade, however with no node $\operatorname{support}(0.52 /-)$.

252

(2) Clade 2: Species from northern Vietnam (O. lacroixi and O. eberhardti) (1.0/100).

253

(3) Clade 3: Joining the $O$. cinereus species group (Indochina and Myanmar), and some taxa from Myanmar (O. splendidus, O. theobaldi, O. cruentatus, O. torquatus, O. planiceps) and Philippines (O. maculatus) (1.0/100).

(5) The newly discovered Oligodon sp. from Bidoup - Nui Ba NP is reconstructed as a sister lineage with respect to two specimens of $O$. annamensis from Vietnam and Cambodia $(1.0 / 100) ;$ O. octolineatus from Sundaland tends to group with this clade, however with no node support (0.62/-). All these species are clustered together with Clade 4 with strong support (1.0/100) (see Figure 2).

Sequence divergence. The uncorrected $p$-distances for the 16S rRNA gene fragment 266 among and within examined Oligodon species are presented in Table 3. Intraspecific distances varied significantly and ranged from $p=0 \%$ in a number of examined species to $p=2.3 \%$ in the $O$. cinereus complex and $p=2.8 \%$ in the $O$. cyclurus complex, what is most likely explained by incomplete taxonomy of these groups (Green et al., 2010; David et al., 2008, 2012); a more detailed study including topotype materials on these species complexes is required. 
272 (between $O$. chinensis and $O$. formosanus) to $p=8.5 \%$ (between $O$. maculatus and $O$.

273 octolineatus) (Table 3). The newly discovered Oligodon sp. lineage from Bidoup - Nui Ba NP is

274 highly divergent from other congeners and is most closely related to $O$. annamensis with $p=3.3 \%$

275 of sequence divergence in 16S rRNA gene between these taxa. This divergence value is notably

276 higher than the genetic differentiation between many other recognized Oligodon species (see

277 Table 3), thus suggesting that the divergence between Oligodon sp. and O. annamensis likely

278 reached species status. Genetic divergence between Vietnamese and Cambodian populations of

279 O. annamensis is minimal and comprised $p=0.9 \%$ of substitutions (Table 3).

280

281

282

283

284

285

286

287

288

289

290

291

292

\section{Systematics}

Our mtDNA-genealogy of Oligodon demonstrated that Oligodon sp. from Bidoup - Nui Ba NP represents a new previously unknown lineage, sister to $O$. annamensis; both species are clustered with the O. taeniatus and O. cyclurus species groups with strong support. Though genetic divergence between Cambodian and Vietnamese populations of $O$. annamensis, separated from each other by over $600 \mathrm{~km}$ distance, is small $(\mathrm{p}=0.9 \%)$; genetic differentiation between Oligodon sp. from Bidoup - Nui Ba NP and O. annamensis is much higher $(\mathrm{p}=3.3 \%)$ and reaches species-level (see Table 3). We thus confirm the identification of the Cambodian population as $O$. annamensis (previously described by Neang and Hun 2013), and also provide a morphological analysis of all presently known specimens of O. annamensis (see Table 4). Our results are further corroborated by our morphological analysis (see below), which uncovered significant differences between Oligodon sp. from Bidoup - Nui Ba NP, O. annamensis and other 
293

294

295

296

297

298

299

300

301

302

303

304

305

306

307

308

309

310

311

312

313

314

315

congeners. These results support our hypothesis that this recently discovered lineage of Oligodon represents an undescribed species, which we describe below:

Oligodon rostralis sp. nov.

(Figures 3-7; Tables 4-5)

Holotype. SIEZC 20201, adult male from Bidoup - Nui Ba National Park, ca. 6 km northwards from Da Nhim village, Da Chais Commune, Lac Duong District, Lam Dong Province, southern Vietnam $\left(12.1518^{\circ} \mathrm{N}, 108.5279^{\circ} \mathrm{E}\right.$; elevation $1622 \mathrm{~m}$ a.s.1.), collected on a steep slope near to mountain summit in montane evergreen pine forest by Bang Van Tran and Linh Hoang Nguyen at 23h on June 13, 2017.

Diagnosis. The new species is assigned to the genus Oligodon Fitzinger, 1826 on the basis of its phylogenetic position and the following morphological attributes: posterior maxillary teeth enlarged and compressed; head short, barely distinct from neck; eye well-developed with round pupil; rostral enlarged; body cylindrical with smooth scales; ventrals rounded; subcaudals paired. Oligodon rostralis sp. nov. is distinguished from its congeners by a combination of the following morphological characters: medium size in adults (male TL $=582 \mathrm{~mm}$ ); head small and broad with long largely protruding snout; 15 dorsal scale rows at neck and midbody and 13 rows before vent; ventrals 167, subcaudals 47 in male; single preocular, single postocular; loreal and presubocular absent; six supralabials, third and fourth entering orbit; six infralabials, anterior four contacting chin shields; internasals separate from prefrontals; nasal divided; single anterior and two posterior temporals; cloacal plate undivided; comparatively short hemipenis, forked in anterior one third of their length, extending to 8th subcaudal, lacking spines and papillae, bearing 
316 prominent transverse flounces and distal calyces; six maxillary teeth, the posterior three being

317 enlarged; dark temporal streak present, edged with white; 14+4 large dark-brown dorsal

318 blotches; bright-orange vertebral stripe on tail and dorsum; and ventral surfaces in life cream

319 with quadrangular spots.

320

Description of holotype. Measurements and scale counts of the holotype are presented in

321

322

323

324

325

326

327

328

329

330

331

332

333

334

335

336

337

338
Table 4. Adult male of medium size (TL $582 \mathrm{~mm}$ ), body robust and cylindrical (Figure 3); SVL $468 \mathrm{~mm}$; head small, comparatively short and wide $(\mathrm{HW} / \mathrm{HL}=73.2 \%)$, ovoid in dorsal view, faintly distinct from the poorly defined neck; tail quite long (19.6\% of total length), $114 \mathrm{~mm}$ in length; robust, abruptly tapering; eye small, comprising approximately $13.5 \%$ of the head length; snout long, protruding ( $\mathrm{SnL} / \mathrm{HL}$ ratio $43.6 \%$ ); eye diameter much shorter than the distance between eye and nostril; pupil round;

Body scalation. Dorsal scales smooth, in 15-15-13 rows, scale row reduction from 15 to 13 at ventral 113; vertebral scales similar to other dorsal scales in size and shape; outermost dorsal scales slightly enlarged; 167 ventrals; cloacal plate entire; 47 subcaudals, all paired, terminal caudal scale in a shape of sharply pointed cap (Figure 3, B).

Head scalation. Details of head scalation are shown in Figure 4. From dorsal view (Figure 4, A-B), head scalation comprising single rostral, two internasals, two prefrontals, two supraoculars, single frontal, and two parietals. Rostral large, thick, wider than high, extending on to the dorsal surface of the snout, visible from above, pointed posteriorly and inserting deeply between internasals, with a deep crease ventrally, contacting nasals, internasals and first supralabial on both sides; the portion of rostral visible from above shorter than its distance from frontal; internasals sub-rectangular, in broad contact, shorter than prefrontals, each contacting rostral, prefrontal, internasal and paired nasals on both sides; prefrontals large, pentagonal, wider 
339 than long and larger than internasals, curving dorsolaterally into loreal region, each contacting

340 internasal and posterior portion of nasal anteriorly, second supralabial laterally, and preocular,

341 supraocular and frontal posteriorly; supraoculars subrectangular, elongated, widening

342 posteriorly, approximately half as wide as long, contacting the orbit, preocular and postocular

343 laterally, prefrontal, frontal and parietal medially; frontal large, pentagonal, longer than wide,

344 narrowing posteriorly, posterior angle rather acute, contacting prefrontals, supraoculars and

345 parietals on both sides; parietals irregularly trapeziform, about 1.5 time larger than frontal,

346 anteriorly contacting frontal, supraoculars and postoculars on each side, bordered posteriorly by

347 five small scales and laterally by the first and upper second temporals; no enlarged nuchal scales

348 present.

349 In lateral view (Figure 4, C-D), head scalation comprising a sub-rectangular nasal, 350 vertically divided by prominent suture and pierced by large nostril, nasal on each side contacting 351 rostral anteriorly, internasal and prefrontal dorsally, and first two supralabials ventrally; loreal 352 and presubocular scales absent; 1/1 rectangular preocular, notably higher than wide, separated 353 from nasal by the lateral part of the prefrontal, also contacting second and third supralabials 354 ventrally and supraocular dorsally; 1/1 rectangular postocular, almost equal in size to preocular, contacting fourth and fifth supralabials ventrally, anterior temporal and parietal posteriorly and supraocular dorsally; six supralabials: I. the smallest, in contact with nasal, II. in contact with nasal, prefrontal and preocular, III. in contact with preocular and the orbit, IV. in contact with the orbit and postocular, V. in contact with postocular, anterior temporal and lower posterior temporal, VI. in contact with lower posterior temporal and scale dorsally, and with two smaller 360 scales posteriorly, V. and VI. strongly enlarged; supralabial scale size formula:

$361 \mathrm{I}<\mathrm{II}<\mathrm{III}=\mathrm{IV}<\mathrm{V}<\mathrm{VI} ; 1+2$ temporals on each side, the upper ones pentagonal, elongated and 
362 narrow, upper posterior temporal slightly larger than the anterior, the lower posterior temporal

363 rhomboid, ca. two times smaller than the upper ones, posteriorly contacting an enlarged scale of 364 same size.

365 In ventral view (Figure 4, E-F), 6/6 infralabials: I. in contact with mental anteriorly, in 366 contact with each other medially; anterior three in contact with anterior chin shield; the fourth

367 largest and touching posterior chin shield; mental small, triangular; $2 / 2$ enlarged, elongated chin 368 shields, anterior pair twice as long as the posterior pair; three small gular scales between 369 posterior chin shields and first preventral.

370 Dentition. Maxillary teeth 6, curved posteriorly, smaller and shorter anteriorly; posterior

371 three being notably enlarged, flattened and kukri-shaped.

372 Hemipenial morphology. Right hemipenis was everted prior to preservation and is shown 373 in Figure 5. Hemipenis rather short, the everted organ hardly reaching $8^{\text {th }}$ subcaudal; bilobed, 374 bifurcating at distal fifth of its length; organ semi-capitate and semi-calyculate; the sulcus 375 spermaticus is bifurcated at around the proximal one-fifth of the hemipenial body and centrolineal along both lobes (Figure 5, A). The sulcal surface of hemipenis is mostly smooth

377 (Figure 5, A), laterally and on asulcal surface hemipenis covered with several fleshy flounces, lacking spines or papillae-like structures (Figure 5, B); distal ends of hemipenial lobes with small 379 indistinct calyces. white reticulation between scales; dorsal pattern consisting of 18 large irregular blackish butterfly-shaped blotches, of which 14 are located on body and 4 on tail, the distances between two blotches comprises ca. 8-10 dorsal scale lengths; a bright orange vertebral stripe running 384 from the base of the head to the tail tip; vertebral stripe width comprising from one to three 
385 dorsal scale rows; some dorsal scales edged with dark-brown forming an indistinct speckled or

386 dashed pattern between blotches, lower rows of dorsal scales fringed with white. Dorsal ground

387 color along head is grayish-brown (Figure 6, B), a butterfly-shaped marking with rusty tint with

388 a rounded dark spot located on frontal, three separated dark-brown chevrons (one short between

389 the eyes, forming two dark brown streaks running across the eye to the angle of the mouth; and

390 two longer ones running from frontal postero-ventrally to neck and posteriorly to the base of the

391 head, respectively); throat and ventral underside pale-cream laterally with alternating

392 quadrangular black spots scattered from throat until tail (Figure 7, A); underside of tail orange-

393 cream.

Colouration (in preservative). (Figure 3), after two years in alcohol, coloration faded but

pattern remained unchanged; body brown, vertebral stripe became somewhat dark-orange and

less distinct (Figure 3, A); dorsal blotches and head marking dark brown with blackish margins

remained unchanged; throat, venter and tail underside cream-white, black quadrangular spots

remained unchanged (Figure 3, B).

Etymology. The specific name "rostralis" is a Latin adjective in the nominative singular, masculine gender, derived from Latin words "rostrum" for "snout" or "beak" in reference to

protruding snout distinctive for the new species. We suggest the following common names for

the new species: "Long-snouted kukri snake" (English), "Rắn khiếm mõm dài" (Vietnamese), and 403 "Dlinnorylyi oligodon" (Russian).

Distribution. At present the new species is known only from the type locality in Bidoup 405 - Nui Ba NP, in the eastern part of Langbian Plateau, southern Vietnam (see Figure 1, locality 1). This montane area is characterized by high levels of local endemism (Nazarov et al., 2012; 
407 Poyarkov et al., 2014, 2015a, 2015b, 2017, 2019b; Stuart et al., 2011; Rowley et al., 2016);

408 further research is needed to clarify the distribution of the new species.

409 Habitat and natural history. The type specimen was collected on the steep slope close

410 to the mountain summit (Figure 7), at late night (23h). The animal was found on ground in leaf

411 litter on the edge of the mixed-pine forest (dominated by Pinus keysia Royle ex Gordon) and

412 evergreen montane broadleaf forest (dominated with trees of the families Fabaceae, Fagaceae,

413 and few large pine trees of Pinus keysia, with understory consisting mostly of Poaceae -

414 different species of bamboo) (Figure 7, B). In the pine forest, understory is dominated by

415 Fagaceae family while ground is covered mostly by grasses and receives high grazing impact by

416 livestock from the villages nearby. In the type locality the new species was recorded in sympatry

417 with some other species of reptiles, including Cyrtodactylus bidoupimontis Nazarov, Poyarkov,

418 Orlov, Phung, Nguyen, Hoang \& Ziegler, Scincella rufocaudata (Darevsky \& Nguyen), and

419 Pareas hamptoni (Boulenger).

420 Phylogenetic position. Oligodon rostralis sp. nov. is suggested as a sister species of $O$.

421 annamensis (Figure 2), from which it is genetically divergent with p-distance $3.3 \%$ in $16 \mathrm{~S}$ rRNA

422 gene (Table 3). Both species are clustered together with the O. cyclurus and O. taeniatus species

423 groups (Figure 2).

424 Comparisons. Morphological diagnostics of species based exclusively on hemipenial 425 morphology is often complicated due to insufficiency of data and certain controversy in 426 describing hemipenis character states in Oligodon existing in literature (Smith, 1943; Wagner, 427 1975; Vassilieva, 2015); scalation and coloration features often might be more useful for species 428 identification (Pauwels et al., 2002; David et al., 2008, 2012; Neang et al., 2012; Nguyen et al., 429 2016, 2017). By having 15-15-13 dorsal scale rows, Oligodon rostralis sp. nov. can be 
430 distinguished from other species inhabiting mainland Southeast Asia having greater number of

431 MSR, namely all members of the O. cyclurus species group: O. cyclurus (Cantor) (19 or 21); O.

432 formosanus (Günther) (19); O. ocellatus (Morice) (19); O. fasciolatus (Günther) (21 or 23); O.

433 kheriensis Achraji \& Ray (19); O. juglandifer (Wall) (19); O. chinensis (Günther) (17); O.

434 saintgironsi David, Vogel \& Pauwels (17 or 18); O. culaochamensis Nguyen, Nguyen, Nguyen,

435 Phan, Jiang \& Murphy (17); O. condaoensis Nguyen, Nguyen, Le \& Murphy (17); O. macrurus

436 (Angel) (17); O. arenarius Vassilieva (17) and O. cattienensis Vassilieva, Geissler, Galoyan,

437 Poyarkov, Van Devender \& Böhme (17); phylogenetic position of the latter two species is 438 unclear.

Similarly, by having 15 MSR the new species can be diagnosed from the members of the

O. taeniatus species group: O. taeniatus (Günther) (19); O. barroni (Smith) (17); O. mouhoti

441 (Boulenger) (17); O. pseudotaeniatus David, Vogel \& Van Rooijen (17); O. moricei David,

442 Vogel \& Van Rooijen (17) and O. deuvei David, Vogel \& Van Rooijen (17).

Most members of the $O$. cinereus species group, which all are believed to have an unforked hemipenis (vs. bilobed hemipenis in the new species; see Green et al., 2010), can be also distinguished from Oligodon rostralis sp. nov. by larger MSR: O. cinereus (Günther) (17); O. nagao David, Nguyen, Nguyen, Jiang, Chen, Teynié \& Ziegler (17); O. joynsoni (Smith) (17);

447 O. saiyok Sumontha, Kunya, Dangsri \& Pauwels (17); O. huahin Pauwels, Larsen, 448 Suthanthangjai, David \& Sumontha (17), and O. albocinctus (Cantor) (19 or 21); another 449 member of the $O$. cinereus species group - O. inornatus (Boulenger) has $15 \mathrm{MSR}$ and is 450 compared with the new species below.

452 of Oligodon with 15 or 13 dorsal scale rows appear to be the most pertinent (as the number of 
453 MSR may vary between these two values due to the position of the dorsal scale row reduction, 454 see David et al., 2012); it is summarized in Table 5. From most species with 15 or 13 MSR, the 455 new species can be distinguished by absence of loreal vs. loreal present in O. eberhardti 456 Pellegrin; O. inornatus; O. kampucheaensis Neang, Grismer \& Daltry; O. jintakunei Pauwels, 457 Wallach, David, Chanhome (vestigial loreal); O. planiceps (Boulenger); O. torquatus 458 (Boulenger); O. dorsalis (Gray) and O. melaneus Wall (vestigial loreal). By presence of an entire 459 cloacal plate Oligodon rostralis sp. nov. can be diagnosed from those species who have the 460 cloacal plate divided, namely from O. catenatus (Blyth), O. eberhardti, O. lacroixi Angel \& 461 Bourret, O. jintakunei, O. lungshenensis Zheng \& Huang, O. ornatus Van Denburgh, O. hamptoni Boulenger, O. mcdougalli Wall, O. planiceps, O. torquatus, O. dorsalis, O. melaneus, and O. erythrorhachis Wall. By having internasals separate from prefrontals the new species can be readily diagnosed from those Oligodon species which have these scales fused, including $O$. catenatus, O. eberhardti, O. lacroixi, O. jintakunei, O. brevicauda and O. hamptoni. By having a 466 single postocular scale Oligodon rostralis sp. nov. is distinguished from those species which have two postocular scales: O. catenatus, O. lacroixi, O. inornatus, O. kampucheaensis, O. lungshenensis, O. hamptoni, O. planiceps, O. torquatus, O. melaneus, O. brevicauda and $O$. erythrorhachis. The new species can be further distinguished from O. brevicauda by having a single preocular scale (vs. 2 preoculars). By having six supralabials the new species can be distinguished from Oligodon species with five (O. lacroixi, O. hamptoni, and O. planiceps), seven (O. jintakunei, O. mcdougalli, O. torquatus, O. dorsalis, O. melaneus, O. brevicauda and O. erythrorhachis), or eight (O. inornatus and O. kampucheaensis) supralabials. 
476 However, the new species can be distinguished from males of $O$. annamensis by the following 477 combination of morphological characters: (1) greater number of dorsal scale rows, DSR formula 478 15-15-13 (vs. DSR formula 13-13-13 in O. annamensis); (2) hemipenis bilobed, lobes 479 bifurcating at distal third of body with flounces and lacking papillae (vs. hemipenis bilobed and 480 elongate, lobes bifurcating proximally with papillae and transverse ridges in $O$. annamensis), (3) 481 nasal vertically divided (vs. nasal entire in O. annamensis); (4) generally larger total length, 582 $482 \mathrm{~mm}$ (vs. maximal total length $412 \mathrm{~mm}$ in $O$. annamensis); (5) generally wider head, HW/HL 483 ratio $73.2 \%$ (vs. $\mathrm{HW} / \mathrm{HL}$ ratio $53.6-56.3 \%$ in $O$. annamensis males, and $61.7 \%$ in female 484 holotype; see Table 4); (6) generally higher number of subcaudals, 47 (vs. 30-46 in $O$. 485 annamensis); (7) dorsal pattern consisting of large dark butterfly-shaped blotches and a light 486 middorsal orange stripe (vs. white narrow crossbars edged with black and no middorsal stripe in O. annamensis); (8) ventral color in life cream-white with black quadrangular spots not forming 488 transverse bars (vs. ventral surfaces in life bright coral-red to bright orange with black quadrangular spots forming transverse bars in O. annamensis) (see Tables 4 and 5). Finally, the new species is distinguished from $O$. annamensis by a significant divergence in mtDNA gene sequences (up to $3.3 \%$ of substitutions in 16S rRNA gene, see Table 3).

492

493

\section{Additional information on Oligodon annamensis Leviton, 1953}

495

Oligodon annamensis Leviton, 1953, Jour. Washington Acad. Sci., 43(12):422. Figures 8-11; Table 4.

496

Holotype. USNM 90408, young female from "Blao, Haut Donai, Annam, French Indo497 China" (today environs of Bao Loc, Lam Dong Prov., Vietnam), collected by E. Poilane on 498 March 11, 1933 (Figure 8). 
Referred specimens. Three male specimens, including MNHN 8815, young male from

500

501

502

503

504

505

506

507

508

509

510

511

512

513

514

515

516

517

518

520

521

519 Variation. Morphological data of all presently known specimens of $O$. annamensis are

Blao, Haut Donai, Station Agricole, collected by E. Poilane on March 11, 1933 (Figure 9).

MNHN 8815, young male from "Blao, Haut Donai, Station Agricole”, collected by E. Poilane on March 11, 1933 (Figure 9); ZMMU R-14304, adult male from Chu Pan Phan Mt., Chu Yang Sin NP, Khue Ngoc Dien Comm., Krong Bong Dist., Dak Lak Prov., Vietnam (12.3950 N, $108.3503^{\circ} \mathrm{E} ; 1050 \mathrm{~m}$ a.s.1.), collected by N.A. Poyarkov on April 14, 2012, described herein (Figure 10); and CBC 01899, young male from Phnom Samkos WS, Pursat Prov., Cambodia $\left(12.1690^{\circ} \mathrm{N}, 102.9721^{\circ} \mathrm{E} ; 916 \mathrm{~m}\right.$ a.s.1.), collected by Hun Seiha on April 26, 2012, 1933 (Figure $11)$.

Revised diagnosis. An Oligodon with medium body size in adults (adult male TL up to $412 \mathrm{~mm}$ ); head small, comparatively narrow, snout not protruding; 13 dorsal scale rows at neck, midbody and before vent; ventrals 146-157, subcaudals 43-46 in males; ventrals 170, subcaudal 30 in female; single preocular, single postocular; loreal and presubocular absent; generally six supralabials, third and fourth entering orbit; six infralabials, anterior three or four contacting the first chin shield; internasals separate from prefrontals; nasal entire; single anterior and one or two posterior temporals; cloacal plate entire; hemipenis deeply bilobed, bearing two long and thin papillae, reaching the $20^{\text {th }}$ subcaudal; 7-8 maxillary teeth; broad dark temporal streak; ground color on dorsum dark brown, 9-10+2-5 light crossbars edged with black on dorsum and tail; vertebral stripe absent; and ventral surfaces in life coral-red to orange with black transverse bars or quadrangular spots. summarized in Table 4; color pattern of all O. annamensis specimens is remarkably similar (Figures 8-11). The holotype of $O$. annamensis, USNM 90408, corresponds well to the original 
522 description by Leviton (1953) (Figure 8), thus we do not provide its formal redescription. The 523 type specimen is a female with several morphological characters different from the known male 524 specimens (see Table 4): it has a relatively shorter tail, RTL 11.7\% (vs. RTL 16.6-19.7\% in 525 three males), a greater number of ventrals, 170 (vs. 146-157 in males), and a lesser number of 526 subcaudals, 30 (vs. 43-46 in males). The second already known specimen of O. annamensis, 527 MNHN 8815, a subadult male, was described in detail by Leviton (1960) (Figure 9). Though in 528 general morphology of MNHN 8815 corresponds well to the description by Leviton (1960), we 529 found several differences in scale counts: MNHN 8815 has 146 ventrals +2 preventrals (vs. 159 530 ventrals, as stated by Leviton, 1960) (courtesy of P. David). The reasons behind such significant 531 differences in scale counts remain unclear; this result further underlines the importance of 532 double-checking specimens preserved in historical collections in taxonomic practice.

533 The newly reported specimen of $O$. annamensis from Vietnam, ZMMU R-14304, was 534 collected from Chu Yang Sin NP in Dak Lak Province at the northern edge of Langbian Plateau 535 (see Figure 1, locality 3). This specimen is an adult male and has the largest total length of all 536 known O. annamensis specimens (412 mm); in scalation and coloration characters it agrees very 537 well with the original description (Leviton, 1953) and the description of male specimen by 538 Leviton (1960) (see Table 4). The tail of ZMMU R-14304 was dissected for examination of 539 hemipenial structures; in full accordance with description by Leviton (1960) this specimen had 540 deeply bilobed hemipenes each bearing two long and thin appendages seen in situ (papillae sensu 541 Smith, 1943), reaching the $20^{\text {th }}$ subcaudal. Coloration of ZMMU R-14304 in life is shown in 542 Figure 10; among other features, the characteristic coral-red background coloration of the ventral 543 surfaces and black quadrangular spots forming complete transverse bars appear to be diagnostic 
544 from Oligodon rostralis sp. nov. (vs. in life ventral surfaces cream-white, black spots do not

545 form transverse bars in the new species).

546 We present additional morphological information (see Table 4) and photos in life (Figure

547 11) of the single known Cambodian specimen of O. annamensis CBC 01899 (see Figure 1,

548 locality 4) described by Neang \& Hun (2013). Based on relative tail length (16.6\%) this

549 specimen is identified as male. In accordance with earlier results of Neang \& Hun (2013) it

550 shows certain morphological differences from the Vietnamese specimens, namely: having 6/5

551 supralabials of which 3-4/2-3 touching the orbit (vs. 6/6 and 3-4/3-4 in Vietnamese specimens);

552 infralabials I-III contacting chin shields (vs. I-IV in Vietnamese specimens); posterior temporal

553 single (vs. two posterior temporals in Vietnamese specimens); ventral coloration in life orange

554 red with black markings not forming transverse bars, see Figure 11, B (vs. coral-red belly getting

555 lighter anteriorly; black markings form numerous transverse bars in Vietnamese specimen, see 556 Figure 10, B).

557 Distribution. To date O. annamensis is reliably known from two provinces of southern 558 Vietnam (Lam Dong and Dak Lak), where it was recorded in montane forests of Langbian 559 Plateau at elevations around $1000 \mathrm{~m}$ a.s.l., and from similar elevations in montane forests of 560 Phnom Samkos Mt. in the western part of the Cardamoms, Pursat, Cambodia. The record of $O$. 561 annamensis from Dak Lak Province is a range extension and the first provincial record of this 562 species.

563 Etymology. The specific name "annamensis" is a Latin adjective derived from "Annam", 564 the historical name of Truong Son Mountains and central Vietnam. Common name in English: 565 “Leviton's kukri snake" (English), "Rắn khiếm trung bộ" (Vietnamese), and “Annamskiy 566 oligodon" (Russian). 


\section{DISCUSSION}

569

570

Our study reports on a new species of Oligodon from southern Vietnam, Oligodon

571

rostralis sp. nov., and provides new data on distribution, taxonomy and phylogenetic position of

O. annamensis, including the first life photographs of this rare species and a range extension and first provincial record of $O$. annamensis for Dak Lak Province of Vietnam. We also confirm the previous identification of a specimen from Cardamom Mountains in Cambodia (Neang \& Hun,

575 2013) as $O$. annamensis based on genetic and morphological lines of evidence. Despite the observed minor morphological differences and geographic isolation, genetic differentiation

577 between Cambodian and Vietnamese populations of $O$. annamensis is quite small and corresponds to common intraspecific levels of divergence in snakes $(p=0.9 \%$, see Table 3$)$.

Hence, O. annamensis has a disrupted range confined to Langbian Plateau in the east and to

Cardamom Mountains in the west and separated by the Mekong River valley. Interestingly, a similar distribution pattern was recently reported for a number of lizard taxa inhabiting

582 Indochina (e.g., Grismer et al., 2019, Poyarkov et al., 2019a), but was never recorded in 583 Indochinese amphibians (Geissler et al., 2015b).

584 The genus Oligodon is traditionally classified in informal species groups on the basis of 585 the hemipenial morphology, number of dorsal scale rows and other characters (Smith, 1943; 586 David et al., 2008, 2012; Vassilieva et al., 2013; Vassilieva, 2015). The role of hemipenial 587 morphology in delimiting clades within Oligodon was also partially confirmed based on 588 phylogenetic analysis by Green et al., (2010). Among the species with available data on 589 hemipenial morphology, only the species groups of $O$. taeniatus and $O$. cyclurus have bilobed 
590 hemipenes, while in other groups copulative organs are unilobed (Green et al., 2010). Oligodon

591 rostralis $\mathbf{s p . ~ n o v . ~ s h o w s ~ a ~ s i g n i f i c a n t ~ m o r p h o l o g i c a l ~ s i m i l a r i t y ~ t o ~ O . ~ a n n a m e n s i s ~ - ~ a ~ s p e c i e s ~ w i t h ~}$

592 unclear phylogenetic position. Leviton (1960), describing hemipenial morphology of the only

593 known male specimen, showed that $O$. annamensis has deeply bilobed hemipenis with papillae,

594 basing on what he proposed that this species may be a part of the "taeniatus-cyclurus-complex"

595 (Leviton, 1953, 1960). Our observations on additional specimens of O. annamensis (see above)

596 confirm the presence of deeply bifurcated hemipenes with papillae in this species. Oligodon

597 rostralis sp. nov. also showed a forked hemipenis morphology, though lacking papillae. Our

598 phylogenetic analysis suggests sister relationships between Oligodon rostralis sp. nov. and $O$.

599 annamensis and places these two species in one clade with the members of the "taeniatus-

600 cyclurus-complex", therefore confirming earlier hypothesis of Leviton $(1953,1960)$. Finally, our

601 phylogeny also suggests that $O$. lacroixi is a sister species of $O$. eberhardti and is not closely

602 related to O. annamensis or Oligodon rostralis sp. nov. despite certain morphological similarity

603 between these species (Orlov et al., 2010).

604 The description of Oligodon rostralis sp. nov. brings the number of Oligodon species

605 known for Vietnam to 24, thus making the country a local center of Oligodon diversity in

606 Southeast Asia. Our work provides further evidence on high herpetofaunal diversity and 607 endemism in Langbian Plateau, which mostly has been discovered only recently (e.g. Chen et al., 608 2018; Duong et al., 2018; Geissler et al., 2015a, 2015b; Hartmann et al., 2013; Nazarov et al., 609 2012; Orlov et al., 2008, 2012, Pauwels et al., 2018; Poyarkov et al., 2014, 2015a, 2015b, 2017, 610 2018, 2019a, 2019b; Poyarkov \& Vassilieva 2011; Rowley et al., 2010, 2011, 2016; Stuart et al.,

611 2011; Vassilieva et al., 2014). Despite the impressive increase in species discoveries in the 612 recent years, many isolated montane areas of the Truong Son Mountains, such as the Langbian 
613 Plateau, still remain insufficiently studied and likely cradle even more unknown biodiversity.

614 The need for further biodiversity exploration in southern Indochina is urgent given the ongoing

615 loss of natural habitats due to such intensifying threats as logging, agricultural pressure, road 616 construction and other anthropogenic activities (De Koninck 1999, Laurance 2007, Meyfroidt \&

617 Lambin 2008, Kuznetsov \& Kuznetsova 2011). Further studies on herpetofaunal biodiversity in 618 this region are immediately required for elaboration of effective conservation measures.

619

620 CONCLUSIONS

621 Here, we present new molecular sequence data and an updated mtDNA genealogy for the 622 genus Oligodon, one of the most species rich groups of Asian snakes. We confirm the presence 623 of four main clades within the genus Oligodon, and for the first time report on the phylogenetic 624 placement of several poorly known Oligodon species, including O. annamensis and O. lacroixi. 625 We analyze all available collection material of $O$. annamensis from southern Vietnam and 626 Cambodia and confirm the earlier assignation of Cambodian population from Cardamom 627 Mountains to this species based on both morphological and molecular lines of evidence. Finally, 628 we report on a new species of Oligodon from southern Vietnam, known from a single male specimen. Oligodon rostralis sp. nov. is distinct from all other congeners in a number of 630 morphological diagnostic characters and is morphologically and phylogenetically most closely 631 related to $O$. annamensis, from which it can be easily distinguished in scalation, coloration and 632 mtDNA sequences. We analyze available morphological data on Oligodon species with 15 or 13 633 dorsal scale rows occurring in the mainland Asia, and discuss phylogenetic relationships among 634 them. We provide further evidence for an unprecedented herpetofaunal diversity and endemism 635 in Langbian Plateau, Southern Vietnam. 


\section{ACKNOWLEDGMENTS}

The authors are grateful to Andrei N. Kuznetsov and Leonid P. Korzoun for support and

639

640

641

642

643

644

645

646

647

648

649

650

651

652

653

654

655

656

657

658 organization of fieldwork. We want to thank Japan International Cooperation (JICA) for supporting the field work in Bidoup - Nui Ba National Park through the Sustainable Natural Resource Management Project (SNRM). Further, we thank the managers and staffs of Nippon Koei Co., Ltd. And Bidoup - Nui Ba National Park for their kind cooperation. We sincerely thank our Vietnamese colleagues Nguyen Dang Hoi, Hoang Minh Duc and Le Xuan Son for help and continued support. For permission to study specimens under her care we thank Valentina F. Orlova (ZMMU); Justin Lee (USNM) and Patrick David (MNHN) and Nikolai L. Orlov (ZISP) provided important information on several Oligodon specimens and useful criticism. H. N. Nguyen would like to give special thanks to his supervisor - Dr. Si-Min Lin (NTNU) for his enormous support with academic advices and funding. We are grateful to Patrick David (MNHN), Seiha Hun (Phnompenh), Justin L. Lee (USNM), Jenna L. Welch (USNM) and the National Museum of Natural History, Smithsonian Institution, for providing us photographs of Oligodon specimens. We are thankful to Gernot Vogel, Justin L. Lee, Patrick David and an anonymous reviewer for their useful comments which allowed us to significantly improve the earlier versions of the manuscript.

\section{REFERENCES}

Alencar LR, Quental TB, Grazziotin FG, Alfaro ML, Martins M, Venzon M, Zaher H. 2016. Diversification in vipers: Phylogenetic relationships, time of divergence and shifts in speciation rates. Molecular Phylogenetics and Evolution 105: 50-62.

Peer] reviewing PDF | (2019:10:41846:1:1:NEW 23 Nov 2019) 
659

660

661

662

663

664

665

666

667

668

669

670

671

672

673

674

675

676

677

678

679

680

Chen JM, Poyarkov NA, Suwannapoom C, Lathrop A, Wu YH, Zhou WW, Yuan ZY, Jin JQ, Chen HM, Liu HQ, Nguyen TQ, Nguyen SN, Duong TV, Eto K, Nishikawa K, Matsui M, Orlov NL, Stuart BL, Brown RM, Rowley JJL, Murphy RW, Wang YY, Che J. 2018. Large-scale phylogenetic analyses provide insights into unrecognized diversity and historical biogeography of Asian leaf-litter frogs, genus Leptolalax (Anura: Megophryidae). Molecular Phylogenetics and Evolution 124: 162-171.

Dahn HA, Strickland JL, Osorio A, Colston TJ, Parkinson CL. 2018. Hidden diversity within the depauperate genera of the snake tribe Lampropeltini (Serpentes, Colubridae). Molecular Phylogenetics and Evolution 129: 214-225. DOI:10.1016/j.ympev.2018.08.018

Das I. 2010. A field guide to the Reptiles of South-east Asia. London: New Holland Publishers (UK), Ltd.

David P, Das I, Vogel G. 2008. A revision of the Oligodon taeniatus (Günther, 1861) group (Squamata: Colubridae), with the description of three new species from the Indochinese Region. Zootaxa 1965: 1-49.

David P, Nguyen TQ, Nguyen TT, Jiang K, Chen TB, Teynié A, Ziegler T. 2012. A new species of the genus Oligodon Fitzinger, 1826 (Squamata: Colubridae) from northern Vietnam, southern China and central Laos. Zootaxa 3498: 45-62.

De Koninck R. 1999. Deforestation in Viet Nam. Ottawa: International Research Centre.

Dowling HG. 1951. A proposed standard system for counting ventrals in snakes. British Journal of Herpetology 2: 97-99.

Dowling HG, Savage JM. 1960. A guide to the snake hemipenis: a survey of basic structure and systematic characteristics. Zoologica 45(1): 17-28. 
681 Duong TV, Do DT, Ngo CD, Nguyen TQ, Poyarkov NA. 2018. A new species of the genus

682

683

684

685

686

687

688

689

690

691

692

693

694

695

696

697

698

699

700

701

702

Leptolalax (Anura: Megophryidae) from southern Vietnam. Zoological Research 38(3): $181-196$.

Engelbrecht HM, Branch WR, Greenbaum E, Alexander GJ, Jackson K, Burger M, Conradie W, Kusama C, Zassi-Boulou AG, Tolley KA. 2019. Diversifying into the branches: species boundaries in African green and bush snakes, Philothamnus (Serpentes: Colubridae). Molecular Phylogenetics and Evolution 130: 357-365.

Felsenstein J. 1985. Confidence limits on phylogenies: an approach using the bootstrap. Evolution 39: 783-791.

Figueroa A, McKelvy AD, Grismer LL, Bell CD, Lailvaux SP. 2016. A species-level phylogeny of extant snakes with description of a new Colubrid subfamily and genus. PLoS ONE 11(9): e0161070.

Geissler G, Poyarkov NA, Grismer LL, Nguyen TQ, An HT, Neang T, Kupfer A, Ziegler T, Böhme W, Müller H. 2015a. New Ichthyophis species from Indochina (Gymnophiona, Ichthyophiidae): 1. The unstriped forms with descriptions of three new species and the redescriptions of I. acuminatus Taylor, 1960, I. youngorum Taylor, 1960 and I. laosensis Taylor, 1969. Organisms Diversity \& Evolution 15(1): 143-174.

Geissler P, Hartmann T, Ihlow F, Rödder D, Poyarkov NA, Nguyen TQ, Ziegler T, Böhme W. 2015b. The Lower Mekong: an insurmountable barrier to amphibians in southern Indochina? Biological Journal of Linnean Society 114(4): 905-914.

Gong SP, Auer M, Zhang YY, Zhung GF, Zeng JD. 2007. A new record of Oligodon catenata in Guangdong Province, China. Chinese Journal of Zoology 42(6): 149-150. 
703 Green MD, Orlov NL, Murphy RW. 2010. Toward a Phylogeny of the Kukri Snakes, genus

704

705

706

707

708

709

710

711

712

713

714

715

716

717

718

719

720

721

722

723

724

725 Oligodon. Asian Herpetological Research 1(1):1-21. DOI:10.3724/SP.J.1245.2010.00001

Grismer LL, Wood PL, Quah ESH, Anuar S, Poyarkov NA, Thy N, Orlov NL, Thammachoti P. 2019. Integrative taxonomy of the Asian skinks Sphenomorphus stellatus (Boulenger, 1900) and S. praesignus (Boulenger, 1900), with the resurrection of $S$. annamiticum (Boettger, 1901), and the description of a new species from Cambodia. Zootaxa 4683(3): 381-411. DOI: 10.11646/zootaxa.4683.3.4

Hall TA. 1999. BioEdit: a user-friendly biological sequence alignment editor and analysis program for Windows 95/98/NT. In: Nucleic acids symposium series. London, Information Retrieval Ltd c1979-c2000: 95-98.

Hartmann T, Geissler P, Poyarkov NA, Ihlow F, Galoyan EA, Rödder D, Böhme W. 2013. A new species of the genus Calotes Cuvier, 1817 (Squamata: Agamidae) from southern Vietnam. Zootaxa 3599(3): 246-260.

Huelsenbeck JP, Hillis DM. 1993. Success of phylogenetic methods in the four-taxon case. Systematic Biology 42: 247-264.

Katoh K, Misawa K, Kuma K, Miyata T. 2002. MAFFT: a novel method for rapid multiple sequence alignment based on fast Fourier transform. Nucleic Acids Research 30: 3059-3066.

Kozlov A, Darriba D, Flouri T, Morel B, Stamatakis A. 2018. RAxML-NG: A fast, scalable, and user-friendly tool for maximum likelihood phylogenetic inference. Bio Rxiv: 447110.

Kuznetsov AN, Kuznetsova SP. 2011. Chương 2. Thực vật Vườn Quốc gia Bidoup-Núi Bà [Chapter 2. Vegetation of Bidoup-Nui Ba National Park]. In: Nguyen DH, Kuznetsov AN, eds. Đa dạng sinh học và đặc trưng sinh thái Vườn Quốc gia Bidoup-Núi Bà. Publishing house for Science and Technology, 37-105. [In Vietnamese]. 
726 Laurance WF. 2007. Forest destruction in tropical Asia. Current Science 93(11): 1544-1550.

727 Leviton AE. 1953. A new snake of the genus Oligodon from Annam. Journal of Washington $728 \quad$ Academy of Sciences 43: 422-424.

729 Leviton AE. 1960. Notes on the second specimen of the snake Oligodon annamensis Leviton. 730 The Wasmann Journal of Biology 18: 305-307.

731

732

733

734

735

736

737

738

739

740

741

742

743

744

745

746

747

Meyfroidt P, Lambin EF. 2008. Forest transition in Vietnam and its environmental impacts. Global Change Biology 14(6): 1319-1336. DOI:10.1111/j.1365-2486.2008.01575.x

Nazarov R, Poyarkov NA, Orlov NL, Phung TM, Nguyen TT, Hoang DM, Ziegler T. 2012. Two new cryptic species of the Cyrtodactylus irregularis complex (Squamata: Gekkonidae) from southern Vietnam. Zootaxa 3302: 1-24.

Neang T, Grismer LL, Daltry JC. 2012. A new species of kukri snake (Colubridae: Oligodon Fitzinger 1826) from the Phnom Samkos Wildlife Sanctuary Cardamom Mountains southwest Cambodia. Zootaxa 3388: 41-55.

Neang T, Hun S. 2013. First record of Oligodon annamensis Leviton, 1953 (Squamata: Colubridae) from the Cardamom Mountains of southwest Cambodia. Herpetological Notes 6: $271-273$.

Nguyen SN, Nguyen LT, Nguyen VDH, Phan HT, Jiang K, Murphy RW. 2017. A new species of the genus Oligodon Fitzinger 1826 (Squamata: Colubridae) from Cu Lao Cham Islands central Vietnam. Zootaxa 4286(3): 333-346.

Nguyen SN, Nguyen VDH, Le SH, Murphy RW. 2016. A new species of kukri snake (Squamata: Colubridae: Oligodon Fitzinger 1826) from Con Dao Islands southern Vietnam. Zootaxa 4139(2): 261-273. 
748 Orlov NL, Nguyen SN, Ho CT. 2008. Description of a new species and new records of

749 Rhacophorus genus (Amphibia: Anura: Rhacophoridae) with the review of amphibians and

750

751

752

753

754

755

756

757

758

759

760

761

762

763

764

765

766

767

768

769

770 reptiles diversity of Chu Yang Sin National Park (Dac Lac Province, Vietnam). Russian Journal of Herpetology 15: 67-84.

Orlov NL, Poyarkov Jr. NA, Vassilieva AB, Ananjeva NB, Nguyen TT, Sang NV, Geissler P. 2012. Taxonomic notes on rhacophorid frogs (Rhacophorinae: Rhacophoridae: Anura) of southern part of Annamite Mountains (Truong Son, Vietnam), with description of three new species. Russian Journal of Herpetology 19: 23-64.

Orlov NL, Ryabov SA, Nguyen TT, Nguyen TQ. 2010. Rediscovery and redescription of two rare snake species: Oligodon lacroixi Angel et Bourret, 1933 and Maculophis bellus chapaensis (Bourret 1934) [Squamata: Ophidia: Colubridae] from Fansipan Mountains northern Vietnam. Russian Journal of Herpetology 17(4): 310-322.

Pauwels OSG, Nazarov RA, Bobrov VV, Poyarkov NA. 2018. Taxonomic status of two populations of Bent-toed Geckos of the Cyrtodactylus irregularis complex (Squamata: Gekkonidae) with description of a new species from Nui Chua National Park, southern Vietnam. Zootaxa 4403(2): 307-335.

Pauwels OSG, Wallach V, David P, Chanhome L. 2002. A new species of Oligodon Fitzinger 1826 (Serpentes Colubridae) from Southern Peninsular Thailand. The Natural History Journal of Chulalongkorn University 2(2): 7-18.

Pellegrin J. 1910. Description d'une variété nouvelle de l'Oligodon herberti Boulenger, Provenant du Tonkin. Bulletin de la Société zoologique de France 35: 30-32. [In French].

Pham AV, Nguyen SLH, Nguyen TQ. 2014. New records of snakes (Squamata: Serpentes) from Son La Province Vietnam. Herpetology Notes 7: 771-777. 
771 Posada D, Crandall KA. 1998. Modeltest: testing the model of DNA substitution.

$772 \quad$ Bioinformatics 14: 817-818.

773 Poyarkov [Paiarkov] NA, Vasilieva AB. 2011. Chuong 5. Bò sát- Lưỡng cư Vườn Quốc gia

774 Bidoup-Núi Bà [Chapter 5. Reptiles and Amphibians of Bidoup-Nui Ba National Park]. In:

775 Nguyen DH, Kuznetsov AN, eds. Đa dạng sinh học và đặc trung sinh thái Vườn Quốc gia

776 Bidoup-Núi Bà. Publishing house for Science and Technology, 169-220. [In Vietnamese].

777 Poyarkov NA, Duong TV, Orlov NL, Gogoleva SS, Vassilieva AB, Nguyen LT, Nguyen

778 VHD, Nguyen SN, Che J, Mahony S. 2017. Molecular, morphological and acoustic

779 assessment of the genus Ophryophryne (Anura, Megophryidae) from Langbian Plateau,

780 southern Vietnam, with description of a new species. Zookeys 672: 49-120.

$781 \quad$ DOI:10.3897/zookeys.672.10624

782 Poyarkov NA, Kropachev II, Gogoleva SS, Orlov NL. 2018. A new species of the genus

783 Theloderma Tschudi, 1838 (Amphibia, Anura, Rhacophoridae) from Tay Nguyen Plateau, 784 central Vietnam. Zoological Research 38(3): 156-180.

785

786

787

788

789

790

791

792

793

Poyarkov NA, Orlov NL, Moiseeva AV, Pawangkhanant P, Ruangsuwan T, Vassilieva AB, Galoyan EA, Nguyen TT, Gogoleva SS. 2015b. Sorting out moss frogs: mtDNA data on taxonomic diversity and phylogenetic relationships of the Indochinese species of the genus Theloderma (Anura, Rhacophoridae). Russian Journal of Herpetology 22(4): 241-280.

Poyarkov NA, Rowley JJL, Gogoleva SS, Vassilieva AB, Galoyan EA, Orlov NL. 2015a. A new species of Leptolalax (Anura: Megophryidae) from the western Langbian Plateau, southern Vietnam. Zootaxa 3931(2): 221-252.

Poyarkov NA, Vassilieva AB, Orlov NL, Galoyan EA, Tran TAD, Le DTT, Kretova VD, Geissler P. 2014. Taxonomy and Distribution of Narrow-Mouth Frogs of the Genus 
794

795

796

797

798

799

800

801

802

803

804

805

806

807

808

809

810

811

812

813

814

815

Microhyla Tschudi, 1838 (Anura: Microhylidae) from Vietnam with Descriptions of five new Species. Russian Journal of Herpetology 21: 60.

Poyarkov NA, Geissler P, Gorin VA, Dunayev EA, Hartmann T, Suwannapoom C. 2019a. Counting stripes: revision of the Lipinia vittigera complex (Reptilia, Squamata, Scincidae) with description of two new species from Indochina. Zoological Research 40(5): 358-393. DOI:10.24272/j.issn.2095-8137.2019.052.

Poyarkov NA, Nguyen TV, Orlov NL, Vogel G. 2019b. A new species of the genus Calamaria Boie, 1827 from the highlands of the Langbian Plateau, Southern Vietnam (Squamata: Colubridae). Russian Journal of Herpetology in press.

Pyron RA, Kandambi HK, Hendry CR, Pushpamal V, Burbrink FT, Somaweera R. 2013. Genus-level phylogeny of snakes reveals the origins of species richness in Sri Lanka. Molecular Phylogenetics and Evolution 66(3): 969-978.

Rambaut A, Suchard M, Xie W, Drummond A. 2014. Tracer v. 1.6. Institute of Evolutionary Biology, University of Edinburgh. Available at: http://tree.bio.ed.ac.uk/software/tracer/

Ronquist F, Huelsenbeck JP. 2003. MrBayes 3: Bayesian phylogenetic inference under mixed models. Bioinformatics 19: 1572-1574.

Rowley JJL, Le TTD, Hoang DH, Dau QV, Cao TT. 2011. Two new species of Theloderma (Anura: Rhacophoridae) from Vietnam. Zootaxa 3098: 1-20.

Rowley JJL, Le TTD, Tran TAD, Stuart BL, Hoang DH. 2010. A new tree frog of the genus Rhacophorus (Anura: Rhacophoridae) from southern Vietnam. Zootaxa 2727: 45-55.

Rowley JJL, Tran DTA, Le DTT, Dau VQ, Peloso PLV, Nguyen TQ, Hoang HD, Nguyen TT, Ziegler T. 2016. Five new, microendemic Asian Leaf-litter Frogs (Leptolalax) from the 
816

817

818

819

820

821

822

823

824

825

826

827

828

829

830

831

832

833

834

835

836

southern Annamite mountains, Vietnam. Zootaxa 4085: 63-102. DOI:10.11646/zootaxa.4085.1.3

Smith MA. 1943. The Fauna of British India, Ceylon and Burma including the whole of the Indo-chinese Sub-Region. Reptilia and Amphibia. Vol. III - Serpentes. London: Taylor and Francis.

Stuart BL, Rowley JJ, Tran DTA, Le DTT, Hoang HD. 2011. The Leptobrachium (Anura: Megophryidae) of the Langbian Plateau, southern Vietnam, with description of a new species. Zootaxa 40: 25-40.

Tamar K, Smid J, Gocmen B, Meiri S, Carranza S. 2016. An integrative systematic revision and biogeography of Rhynchocalamus snakes (Reptilia, Colubridae) with a description of a new species from Israel. PeerJ 4: e2769. DOI:10.7717/peerj.2769

Tamura K, Stecher G, Peterson D, Filipski A, Kumar S. 2013. MEGA6: molecular evolutionary genetics analysis version 6.0. Molecular Biology and Evolution 30: 2725-2729.

Taylor EH. 1965. The serpents of Thailand and adjacent waters. University of Kansas Science Bulletin 45(9): 609-1096.

Tillack F, Günther R. 2009. Revision of the species of Oligodon from Sumatra and adjacent islands, with comments on the taxonomic status of Oligodon subcarinatus (Günther, 1872) and Oligodon annulifer (Boulenger, 1893) from Borneo (Reptilia, Squamata, Colubridae). Russian Journal of Herpetology 16 (4): 265-294.

Uetz P, Freed P, Hošek J. 2019. The Reptile Database. Available at http://reptiledatabase.reptarium.cz/ (accessed: 25 August 2019) 
837 Vassilieva AB, Galoyan EA, Gogoleva SS, Poyarkov NA. 2014. Two new species of 838 Kalophrynus Tschudi, 1838 (Anura: Microhylidae) from the Annamite mountains in 839 southern Vietnam. Zootaxa 3796(3): 401-434.

840 Vassilieva AB, Geissler P, Galoyan EA, Poyarkov NA Jr, van Devender RW, Böhme W.

841 2013. A new species of Kukri Snake (Oligodon Fitzinger 1826: Squamata: Colubridae) from 842 the Cat Tien National Park southern Vietnam. Zootaxa 3702(3): 233-246.

843 Vassilieva AB. 2015. A new species of the genus Oligodon Fitzinger 1826 (Squamata: 844 Colubridae) from coastal southern Vietnam. Zootaxa 4058(2): 211-226.

Wagner FW. 1975. A revision of the Asian colubrid snakes Oligodon cinereus (Günther), Oligodon joynsoni (Smith), and Oligodon cyclurus (Cantor). Unpublished MS thesis, Baton Rouge, Louisiana State University.

Wallach V, Williams KL, Boundy J. 2014. Snakes of the world. A catalogue of living and 849 extinct species. CRC Press. 
Table $\mathbf{1}$ (on next page)

Primers used in this study. 


\begin{tabular}{clll}
\hline \multicolumn{1}{c}{ Gene } & \multicolumn{1}{c}{$\begin{array}{c}\text { Primer } \\
\text { name }\end{array}$} & \multicolumn{1}{c}{ Reference } & Sequence \\
\hline 12S rRNA & 12S2LM & Green et al., 2010 & 5'-ACACACCGCCCGTCACCCT-3' \\
& 16S5H & Green et al., 2010 & 5'-CTACCTTTGCACGGTTAGGATACCGCGGC-3' \\
\multirow{2}{*}{ 16S rRNA } & $16 \mathrm{~S} 1 \mathrm{LM}$ & Green et al., 2010 & 5'-CCGACTGTTGACCAAAAACAT-3' \\
& $16 \mathrm{SH} 1$ & Green et al., 2010 & 5'-CTCCGGTCTGAACTCAGATCACGTAGG-3' \\
\multirow{3}{*}{ cyt $b$} & H14910 & Dahn et al., 2018 & 5'-GACCTGTGATMTGAAAAACCAYCGTT-3' \\
& THRSN2 & Dahn et al., 2018 & 5'-CTTTGGTTTACAAGAACAATGCTTTA-3' \\
\hline
\end{tabular}




\section{Table 2 (on next page)}

Sequences and voucher specimens of Oligodon and outgroup taxa used in this study. 


\begin{tabular}{|c|c|c|c|c|c|c|}
\hline No. & Sample ID & Genbank AN & Species & Country & Locality & Reference \\
\hline 1 & SIEZC 20201 & MN395604; MN396765 & Oligodon rostralis $\mathbf{s p . ~ n o v . ~}$ & Vietnam & Lam Dong Prov., Bidoup - Nui Ba NP & this work \\
\hline 2 & ZMMU R-14304 & MN395601; MN396762 & Oligodon annamensis & Vietnam & Dak Lak Prov., Chu Yang Sin NP & this work \\
\hline 3 & CBC 01899 & MN395602; MN396763 & Oligodon annamensis & Cambodia & Pursat Prov., Veal Veng, Samkos WS & this work \\
\hline 4 & ZMMU R-13364 & MN395603; MN396764 & Oligodon lacroixi & Vietnam & Phu Tho Prov., Xuan Son NP & this work \\
\hline 5 & UMMZ201913 & HM591519 & Oligodon octolineatus & Brunei & Tutong Dist., $3 \mathrm{~km} \mathrm{E} \mathrm{of} \mathrm{Tutong}$ & Green et al. (2010) \\
\hline 6 & ROM 35626 & HM591526 & Oligodon chinensis & Vietnam & Cao Bang Prov., Quang Thanh & Green et al. (2010) \\
\hline 7 & ROM 30970 & HM591528 & Oligodon chinensis & Vietnam & $\begin{array}{l}\text { Nghe An Prov., } 24 \mathrm{~km} \mathrm{~W} \text { of Con } \\
\text { Cuong }\end{array}$ & Green et al. (2010) \\
\hline 8 & ROM 34540 & HM591527 & Oligodon chinensis & Vietnam & Hai Duong Prov., Chi Linh & Green et al. (2010) \\
\hline 9 & ROM 31032 & HM591524 & Oligodon chinensis & Vietnam & Vinh Phuc Prov., Tam Dao NP & Green et al. (2010) \\
\hline 10 & ROM30824 & HM591525 & Oligodon chinensis & Vietnam & Tuyen Quang Prov., Pac Ban & Green et al. (2010) \\
\hline 11 & ROM 30823 & HM591529 & Oligodon formosanus & Vietnam & Tuyen Quang Prov., Pac Ban & Green et al. (2010) \\
\hline 12 & ROM30826 & HM591530 & Oligodon formosanus & Vietnam & Vinh Phuc Prov., Tam Dao NP & Green et al. (2010) \\
\hline 13 & ROM30939 & HM591531 & Oligodon formosanus & Vietnam & Cao Bang Prov., $\mathrm{Ba} \mathrm{Be}$ & Green et al. (2010) \\
\hline 14 & ROM 35629 & HM591533 & Oligodon formosanus & Vietnam & Cao Bang Prov., Quang Thanh & Green et al. (2010) \\
\hline 15 & ROM35806 & HM591532 & Oligodon formosanus & Vietnam & Hai Duong Prov., Chi Linh & Green et al. (2010) \\
\hline 16 & ROM32261 & HM591534 & Oligodon ocellatus & Vietnam & Dak Lak Prov., Yok Don NP & Green et al. (2010) \\
\hline 17 & ROM 32260 & HM591521 & Oligodon taeniatus & Vietnam & Dak Lak Prov., Yok Don NP & Green et al. (2010) \\
\hline 18 & ROM37091 & HM591522 & Oligodon taeniatus & Vietnam & Dong Nai Prov., Cat Tien NP & Green et al. (2010) \\
\hline 19 & ROM32464 & HM591523 & Oligodon barroni & Vietnam & Gai Lai Prov., Krong Pa & Green et al. (2010) \\
\hline 20 & USNM520625 & HM591520 & Oligodon cf. taeniatus & Myanmar & Chatthin, 2 km WNW Chatthin WS & Green et al. (2010) \\
\hline 21 & CAS204963 & HM591535 & Oligodon cyclurus & Myanmar & Ayeyarwady Div., Mwe Hauk & Green et al. (2010) \\
\hline 22 & CAS215636 & HM591536 & Oligodon cyclurus & Myanmar & Sagging Div., Alaungdaw Kathapa NP & Green et al. (2010) \\
\hline 23 & ROM37092 & HM591504 & Oligodon cinereus & Vietnam & Dong Nai Prov., Cat Tien NP & Green et al. (2010) \\
\hline 24 & CAS213379 & HM591506 & Oligodon cf. cinereus & Myanmar & Yangon Div., Hlaw Ga NP & Green et al. (2010) \\
\hline 25 & CAS205028 & HM591507 & Oligodon cf. cinereus & Myanmar & Rakhine St., Rakhine Yoma Mts. & Green et al. (2010) \\
\hline 26 & ROM32462 & HM591501 & Oligodon cinereus & Vietnam & Hai Duong Prov., Chi Linh & Green et al. (2010) \\
\hline 27 & ROM29552 & HM591502 & Oligodon cinereus & Vietnam & Vinh Phuc Prov., Tam Dao NP & Green et al. (2010) \\
\hline
\end{tabular}




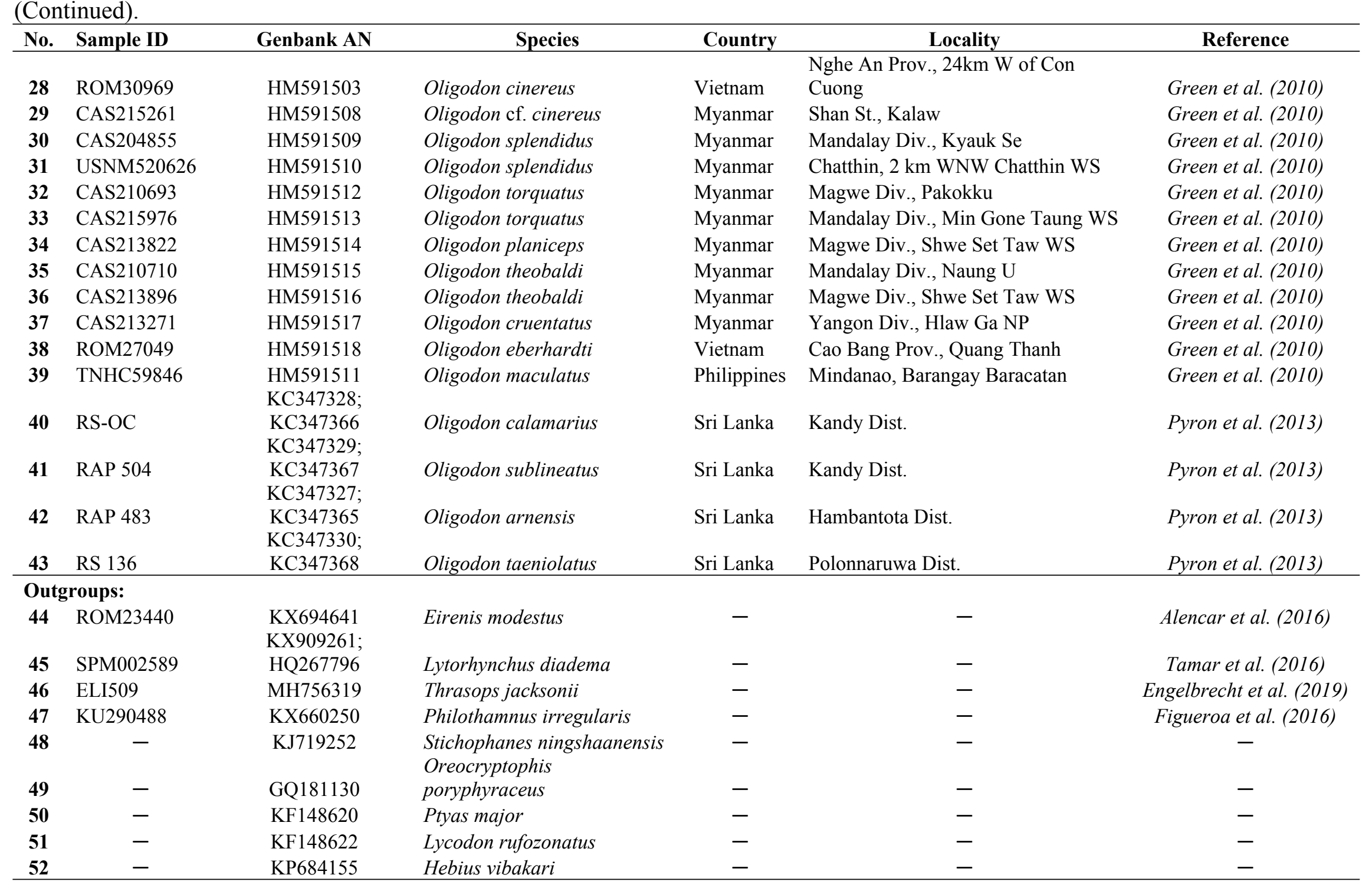




\section{Table 3(on next page)}

Genetic differentiation of Oligodon.

Uncorrected $p$-distance (percentage) between the sequences of 165 rRNA mtDNA gene (below the diagonal), estimate errors (above the diagonal) and intraspecific genetic $p$ distance (on the diagonal) of Oligodon species included in phylogenetic analyses. 


\begin{tabular}{|c|c|c|c|c|c|c|c|c|c|c|c|c|c|c|c|c|c|c|c|c|c|c|c|}
\hline No. & Species & 1 & 2 & 3 & 4 & 5 & 6 & 7 & 8 & 9 & 10 & 11 & 12 & 13 & 14 & 15 & 16 & 17 & 18 & 19 & 20 & 21 & 22 \\
\hline 1 & Oligodon rostralis sp. nov. & - & 0.8 & 1.0 & 0.8 & 1.0 & 0.9 & 0.9 & 1.1 & 1.0 & 1.2 & 1.2 & 1.2 & 1.1 & 1.1 & 1.1 & 1.1 & 1.3 & 1.1 & 1.2 & 1.2 & 1.2 & 1.1 \\
\hline 2 & O. annamensis & 3.3 & 0.9 & 1.1 & 0.8 & 1.0 & 0.9 & 1.0 & 1.0 & 1.0 & 1.0 & 1.2 & 1.0 & 1.0 & 1.1 & 0.9 & 1.2 & 1.0 & 1.0 & 1.1 & 1.0 & 1.2 & 1.0 \\
\hline 3 & O. octolineatus & 4.4 & 4.9 & - & 1.0 & 1.1 & 1.0 & 1.1 & 1.3 & 1.2 & 1.3 & 1.4 & 1.4 & 1.3 & 1.2 & 1.3 & 1.3 & 1.4 & 1.3 & 1.3 & 1.3 & 1.5 & 1.3 \\
\hline 4 & O. taeniatus complex & 3.9 & 3.7 & 5.5 & 0.0 & 0.7 & 0.8 & 0.8 & 0.6 & 0.9 & 1.0 & 1.1 & 1.1 & 0.9 & 0.9 & 0.9 & 1.1 & 1.1 & 1.1 & 1.0 & 1.1 & 1.1 & 1.1 \\
\hline 5 & O. barroni & 5.0 & 5.0 & 6.1 & 2.4 & - & 0.9 & 0.9 & 0.9 & 1.1 & 1.2 & 1.2 & 1.2 & 1.1 & 1.1 & 1.2 & 1.2 & 1.3 & 1.2 & 1.1 & 1.2 & 1.3 & 1.3 \\
\hline 6 & O. formosanus & 3.8 & 4.1 & 5.8 & 3.2 & 4.3 & 0.5 & 0.5 & 1.0 & 0.9 & 1.0 & 1.1 & 1.1 & 0.9 & 1.0 & 1.0 & 1.0 & 1.1 & 0.9 & 1.1 & 1.1 & 1.2 & 1.0 \\
\hline 7 & O. chinensis & 4.5 & 5.0 & 6.5 & 3.2 & 4.3 & 1.8 & 0.7 & 0.9 & 0.9 & 1.1 & 1.1 & 1.1 & 1.0 & 1.0 & 1.1 & 1.1 & 1.1 & 1.0 & 1.1 & 1.2 & 1.3 & 1.1 \\
\hline 8 & O. cyclurus complex & 5.8 & 5.1 & 7.1 & 2.9 & 4.7 & 5.4 & 5.5 & 2.8 & 0.9 & 1.0 & 1.1 & 1.1 & 1.0 & 1.0 & 1.0 & 1.1 & 1.1 & 1.1 & 1.1 & 1.1 & 1.2 & 1.2 \\
\hline 9 & O. ocellatus & 4.8 & 4.8 & 5.7 & 3.9 & 5.0 & 3.9 & 4.1 & 3.7 & - & 1.1 & 1.2 & 1.2 & 1.1 & 1.1 & 1.2 & 1.1 & 1.2 & 1.2 & 1.3 & 1.2 & 1.3 & 1.1 \\
\hline 10 & O. cinereus complex & 6.8 & 6.1 & 7.7 & 6.0 & 7.1 & 6.2 & 6.2 & 6.1 & 6.3 & 2.3 & 0.8 & 0.8 & 0.7 & 0.7 & 0.9 & 0.8 & 0.9 & 0.9 & 0.9 & 0.9 & 1.0 & 1.0 \\
\hline 11 & O. splendidus & 7.2 & 7.0 & 8.1 & 6.1 & 7.2 & 6.7 & 6.2 & 6.9 & 7.0 & 4.0 & 0.4 & 0.8 & 0.8 & 0.8 & 0.9 & 0.8 & 1.1 & 1.0 & 1.0 & 1.0 & 1.0 & 1.1 \\
\hline 12 & O. maculatus & 7.6 & 6.5 & 8.5 & 6.3 & 7.6 & 6.0 & 6.0 & 7.1 & 7.0 & 4.1 & 3.5 & - & 0.6 & 0.7 & 0.7 & 0.8 & 1.0 & 1.0 & 0.9 & 0.9 & 0.9 & 1.0 \\
\hline 13 & O. theobaldi & 5.2 & 4.7 & 6.6 & 3.9 & 5.2 & 4.5 & 5.0 & 5.1 & 5.4 & 3.7 & 3.7 & 2.8 & 0.0 & 0.4 & 0.6 & 0.7 & 0.9 & 0.8 & 0.9 & 1.0 & 0.9 & 0.9 \\
\hline 14 & O. cruentatus & 5.9 & 5.4 & 7.2 & 4.6 & 5.9 & 5.1 & 5.6 & 5.6 & 6.1 & 4.3 & 4.4 & 3.5 & 0.7 & - & 0.7 & 0.8 & 1.0 & 0.8 & 1.0 & 1.0 & 0.9 & 1.0 \\
\hline 15 & O. torquatus & 6.5 & 5.5 & 8.2 & 5.1 & 6.2 & 5.7 & 6.2 & 6.2 & 6.8 & 4.9 & 5.0 & 4.1 & 2.3 & 2.9 & 1.3 & 0.7 & 1.0 & 0.9 & 0.9 & 0.9 & 1.0 & 0.9 \\
\hline 16 & O. planiceps & 6.3 & 6.2 & 7.9 & 5.7 & 6.8 & 5.2 & 5.9 & 6.7 & 6.3 & 5.0 & 5.2 & 4.6 & 2.4 & 3.1 & 3.2 & - & 1.1 & 1.0 & 1.0 & 1.0 & 1.0 & 1.2 \\
\hline 17 & O. eberhardti & 6.6 & 5.9 & 7.5 & 6.4 & 7.7 & 6.3 & 6.1 & 6.6 & 6.6 & 5.4 & 6.6 & 5.3 & 4.4 & 5.1 & 5.4 & 6.4 & - & 0.7 & 1.1 & 1.0 & 1.2 & 1.0 \\
\hline 18 & O. lacroixi & 5.2 & 4.8 & 7.0 & 5.0 & 6.3 & 4.4 & 5.2 & 5.9 & 5.9 & 4.9 & 6.3 & 5.4 & 3.3 & 3.9 & 4.7 & 5.2 & 2.2 & - & 0.9 & 1.0 & 1.0 & 0.9 \\
\hline 19 & O. calamarius & 6.1 & 6.0 & 7.2 & 5.9 & 7.0 & 5.5 & 6.4 & 6.7 & 7.2 & 5.7 & 5.7 & 5.2 & 5.0 & 5.7 & 6.4 & 5.4 & 6.6 & 5.4 & - & 0.8 & 0.9 & 1.0 \\
\hline 20 & O. sublineatus & 6.6 & 5.8 & 7.2 & 6.1 & 7.2 & 5.9 & 6.4 & 6.8 & 7.0 & 5.3 & 5.0 & 4.1 & 4.8 & 5.5 & 5.8 & 5.7 & 5.7 & 5.5 & 3.5 & - & 0.9 & 1.0 \\
\hline 21 & O. taeniolatus & 6.5 & 6.7 & 7.9 & 6.1 & 7.4 & 6.1 & 6.6 & 7.1 & 7.4 & 5.4 & 5.2 & 4.4 & 3.5 & 4.1 & 5.7 & 5.0 & 6.2 & 5.4 & 3.7 & 3.3 & - & 1.1 \\
\hline 22 & O. arnensis & 5.7 & 5.1 & 7.7 & 5.7 & 7.0 & 4.7 & 5.6 & 7.0 & 6.6 & 6.4 & 6.7 & 5.5 & 4.6 & 5.2 & 5.6 & 6.3 & 6.2 & 4.8 & 5.9 & 5.7 & 5.7 & - \\
\hline
\end{tabular}




\section{Table 4 (on next page)}

Morphological data on Oligodon rostralis sp. nov. and all known specimens of $O$. annamensis.

Measurements in $\mathrm{mm}$; for abbreviations see Materials and methods section. An asterisk (*) denotes the holotype of a species. 
A. Measurements and scale counts.

\begin{tabular}{|c|c|c|c|c|c|c|c|c|c|c|c|c|c|c|c|c|c|c|c|}
\hline Museum ID & Sex & SVL & TaL & TL & RTL & HL & HW & HW/HL & SnL & EyeL & FrL & FrW & IOD & IND & DEN & ASR & MSR & PSR & RED 1 \\
\hline \multicolumn{20}{|c|}{ Oligodon rostralis sp. nov. } \\
\hline SIEZC 20201* & $\mathrm{m}$ & 468 & 114 & 582 & $19.6 \%$ & 14.5 & 10.6 & $73.2 \%$ & 6.3 & 2.0 & 5.4 & 4.5 & 6.4 & 3.6 & 6 & 15 & 15 & 13 & 113 \\
\hline \multicolumn{20}{|c|}{ Oligodon annamensis } \\
\hline ZMMU R-14304 & $\mathrm{m}$ & 331 & 81 & 412 & $19.7 \%$ & 13.2 & 7.3 & $55.1 \%$ & 4.2 & 1.8 & 4.0 & 3.4 & 4.8 & 3.6 & 8 & 13 & 13 & 13 & - \\
\hline СBC 01899 & $\mathrm{~m}$ & 152 & 35 & 187 & $18.7 \%$ & 9.7 & 5.2 & $53.6 \%$ & 3.0 & 1.7 & 3.1 & 2.4 & 3.6 & 2.4 & 7 & 13 & 13 & 13 & - \\
\hline MNHN 8815 & $\mathrm{~m}$ & 111 & 22 & 133 & $16.6 \%$ & 8.0 & 4.5 & $56.3 \%$ & 2.5 & 1.4 & 3.0 & 2.5 & 3.5 & 2.3 & $7-8$ & 13 & 13 & 13 & - \\
\hline USNM 90408* & $\mathrm{f}$ & 220 & 29 & 249 & $11.7 \%$ & 9.4 & 5.8 & $61.7 \%$ & 3.0 & 1.5 & 3.3 & 2.6 & 4.1 & 2.3 & 8 & 13 & 13 & 13 & - \\
\hline
\end{tabular}

2

\section{B. Scale counts.}

\begin{tabular}{|c|c|c|c|c|c|c|c|c|c|c|c|c|c|c|c|c|}
\hline Museum ID & VS & SC & Total Sc. & AP & LOR & SL & SL-eye & IL & NAS & IL-contact & IL-CS & PrO & PrsOc & PtO & Ate & Pte \\
\hline \multicolumn{17}{|c|}{ Oligodon rostralis $\mathbf{s p .}$ nov. } \\
\hline SIEZC 20201* & 167 & 47 & 214 & 1 & 0 & 6 & $3-4$ & 6 & $\mathrm{D}$ & 1 & $1-4$ & 1 & 0 & 1 & 1 & 2 \\
\hline \multicolumn{17}{|c|}{ Oligodon annamensis } \\
\hline ZMMU R-14304 & 157 & 43 & 200 & 1 & 0 & 6 & $3-4$ & 6 & $\mathrm{E}$ & 1 & $1-4$ & 1 & 0 & 1 & 1 & 2 \\
\hline CBC 01899 & 148 & 46 & 194 & 1 & 0 & $6 / 5$ & $3-4 / 2-3$ & 6 & $\mathrm{E}$ & 1 & $1-3$ & 1 & 0 & 1 & 1 & 1 \\
\hline MNHN 8815 & $146+2$ & 46 & 192 & 1 & 0 & 6 & $3-4$ & 6 & $\mathrm{E}$ & 1 & $1-4$ & 1 & 0 & 1 & 1 & 2 \\
\hline USNM 90408* & 170 & 30 & 200 & 1 & 0 & 6 & $3-4$ & 6 & $\mathrm{E}$ & 1 & $1-4$ & 1 & 0 & 1 & 1 & 2 \\
\hline
\end{tabular}

4 
8 (Continued).

9 C. Hemipenial morphology and coloration.

\begin{tabular}{|c|c|c|c|c|c|c|c|c|c|c|c|}
\hline Museum ID & $\begin{array}{c}\text { Hemipenis } \\
\text { status }\end{array}$ & $\begin{array}{c}\text { Hemipenis } \\
\text { shape }\end{array}$ & $\begin{array}{c}\text { Hemipenis } \\
\text { ornamentation }\end{array}$ & $\begin{array}{l}\text { Hemipenis } \\
\text { length }\end{array}$ & Body color & $\begin{array}{c}\text { Color } \\
\text { pattern }\end{array}$ & $\begin{array}{c}\text { Body } \\
\text { blotches }\end{array}$ & $\begin{array}{c}\text { Tail } \\
\text { blotches }\end{array}$ & Stripes & Venter & Reference \\
\hline \multicolumn{12}{|c|}{ Oligodon rostralis sp. nov. } \\
\hline SIEZC $20201^{*}$ & $\begin{array}{l}\text { right } \\
\text { everted }\end{array}$ & $\begin{array}{l}1 / 3 \text { forked, } \\
\text { no papillae }\end{array}$ & $\begin{array}{l}\text { flounced, no } \\
\text { spines }\end{array}$ & $\begin{array}{l}\text { reaching 8th } \\
\text { subcaudal }\end{array}$ & $\begin{array}{l}\text { dorsum and } \\
\text { tail greyish- } \\
\text { brown }\end{array}$ & $\begin{array}{l}\text { middorsal } \\
\text { light stripe } \\
\text { and dark } \\
\text { blotches }\end{array}$ & $\begin{array}{l}18 \text { large dark } \\
\text { blotches }\end{array}$ & $\begin{array}{l}4 \text { dark } \\
\text { blotches }\end{array}$ & $\begin{array}{l}\text { light-orange } \\
\text { middorsal } \\
\text { stripe with } \\
\text { indistinct } \\
\text { borders }\end{array}$ & $\begin{array}{l}\text { venter and tail } \\
\text { underside pale- } \\
\text { cream, with } \\
\text { intermittent black } \\
\text { quadrangular } \\
\text { spots; tail in life } \\
\text { light orange }\end{array}$ & this paper \\
\hline \multicolumn{12}{|c|}{ Oligodon annamensis } \\
\hline ZMMU R-14304 & $\begin{array}{l}\text { left } \\
\text { dissected }\end{array}$ & $\begin{array}{l}\text { deeply } \\
\text { forked with } \\
2 \text { papillae }\end{array}$ & $\begin{array}{l}\text { transverse ridges, } \\
\text { no spines }\end{array}$ & $\begin{array}{l}\text { reaching } \\
20 \text { th } \\
\text { subcaudal }\end{array}$ & $\begin{array}{l}\text { dorsum and } \\
\text { tail dark } \\
\text { brown }\end{array}$ & $\begin{array}{l}\text { light cross } \\
\text { bars }\end{array}$ & $\begin{array}{l}10 \text { faint } \\
\text { white cross } \\
\text { bars edged } \\
\text { with black }\end{array}$ & $\begin{array}{l}5 \text { beige } \\
\text { cross } \\
\text { bars }\end{array}$ & no & $\begin{array}{l}\text { coral-red with } \\
\text { numerous black } \\
\text { bars and } \\
\text { qudrangular } \\
\text { blotches }\end{array}$ & this paper \\
\hline CBC 01899 & - & - & - & - & $\begin{array}{l}\text { dorsum and } \\
\text { tail dark } \\
\text { brown }\end{array}$ & $\begin{array}{l}\text { light cross } \\
\text { bars }\end{array}$ & $\begin{array}{l}10 \text { orange } \\
\text { cross bars } 2- \\
3 \text { scales wide }\end{array}$ & $\begin{array}{l}3 \text { orange } \\
\text { cross } \\
\text { bars on } \\
\text { tail }\end{array}$ & no & $\begin{array}{l}\text { orange with } \\
\text { sparse black } \\
\text { subrectangular } \\
\text { blotches }\end{array}$ & $\begin{array}{l}\text { Neang \& } \\
\text { Hun, 2013; } \\
\text { our data }\end{array}$ \\
\hline MNHN 8815 & dissected & $\begin{array}{l}\text { deeply } \\
\text { forked with } \\
2 \text { papillae }\end{array}$ & $\begin{array}{l}\text { transverse ridges, } \\
\text { no spines }\end{array}$ & $\begin{array}{l}\text { reaching } \\
17 \text { th } \\
\text { subcaudal }\end{array}$ & $\begin{array}{l}\text { dorsum and } \\
\text { tail light } \\
\text { brown }\end{array}$ & $\begin{array}{l}\text { light cross } \\
\text { bars }\end{array}$ & $\begin{array}{l}10 \text { white } \\
\text { cross bars } \\
\text { edged with } \\
\text { black }\end{array}$ & $\begin{array}{l}2 \text { white } \\
\text { cross } \\
\text { bars }\end{array}$ & no & $\begin{array}{l}\text { white with dark } \\
\text { quadranglar spots } \\
\text { and bars }\end{array}$ & $\begin{array}{l}\text { Leviton, } \\
\text { 1960; our } \\
\text { data }\end{array}$ \\
\hline USNM 90408* & - & - & - & - & $\begin{array}{l}\text { dorsum and } \\
\text { tail light } \\
\text { brown }\end{array}$ & $\begin{array}{l}\text { light cross } \\
\text { bars }\end{array}$ & $\begin{array}{l}9 \text { white cross } \\
\text { bars edged } \\
\text { with black }\end{array}$ & $\begin{array}{l}3 \text { white } \\
\text { cross } \\
\text { bars }\end{array}$ & no & $\begin{array}{l}\text { white with dark } \\
\text { quadranglar spots } \\
\text { and bars }\end{array}$ & $\begin{array}{l}\text { Leviton, } \\
\text { 1953; our } \\
\text { data }\end{array}$ \\
\hline
\end{tabular}

10 


\section{Table 5 (on next page)}

Comparison of morphological characters of Oligodon rostralis sp. nov. with Indochinese species of Oligodon having 13-15 dorsal scale rows (DSR).

The characters and data for other species taken from Das (2010); Gong et al. (2007); Leviton (1953, 1960); Neang et al. (2012); Neang \& Hun (2013); Orlov et al. (2010); Pauwels et al. (2002); Pellegrin (1910); Pham et al. (2014); Smith (1943); Taylor (1965). Abbreviations: DSR - dorsal scale rows; SL - number of supralabials; SL-E - supralabials touching the eye; IL number of infralabials; NAS - nasal (D - divided, E - entire, PD - partially divided); InN/PF internasal - prefrontal relationships (S - separate, F - fused); PrO - number of preoculars; PtO number of postoculars; AP - cloacal plate (E - entire, D - divided); LOR - loreal (0 - absent, 1 present, * - vestigal); Ate - number of anterior temporals; Pte - number of posterior temporals; VS - number of ventrals; SC - number of subcaudals; DEN - number of maxillary teeth; RTL - relative tail length (in \%). 


\begin{tabular}{|c|c|c|c|c|c|c|c|c|c|c|c|c|c|c|c|c|}
\hline Species & DSR & SL & SL-E & IL & NAS & InN/PF & PrO & PtO & AP & LOR & Ate & Pte & VS & SC & DEN & RTL \\
\hline Oligodon rostralis $\mathbf{s p .}$ nov. & $15-15-13$ & 6 & $3-4$ & 6 & $\mathrm{D}$ & $\mathrm{S}$ & 1 & 1 & $\mathrm{E}$ & 0 & 1 & 2 & 167 & 47 & 6 & 19.6 \\
\hline Oligodon annamensis & $13-13-13$ & 6 & $3-4$ & 6 & $\mathrm{E}$ & $\mathrm{S}$ & 1 & 1 & $\mathrm{E}$ & 0 & 1 & 2 & $148-170$ & $30-46$ & $7-8$ & $11.6-19.7$ \\
\hline Oligodon catenatus & $13-13-13$ & 6 & $3-4$ & 6 & E & $\mathrm{F}$ & 1 & 2 & $\mathrm{D}$ & 0 & 1 & 2 & $179-212$ & $31-43$ & 7 & $12.6-13.3$ \\
\hline Oligodon eberhardti & $13-13-13$ & 6 & $2-3$ & 6 & $\mathrm{E}$ & $\mathrm{F}$ & 1 & 1 & $\mathrm{D}$ & 1 & 1 & 2 & $165-187$ & $31-40$ & $?$ & 15.1 \\
\hline Oligodon lacroixi & $17-15-15$ & 5 & $2-3$ & 6 & $\mathrm{E}$ & $\mathrm{F}$ & 1 & 2 & $\mathrm{D}$ & 0 & 1 & 2 & $162-178$ & $25-34$ & $8-12$ & $10.5-11.5$ \\
\hline Oligodon inornatus & $15-15-15$ & 8 & $4-5$ & 8 & $\mathrm{D}$ & $\mathrm{S}$ & 1 & 2 & $\mathrm{E}$ & 1 & 1 & 2 & $169-174$ & $31-43$ & $10-11$ & 15.5 \\
\hline Oligodon kampucheaensis & $15-15-15$ & 8 & $4-5$ & 8 & $\mathrm{D}$ & $\mathrm{S}$ & 1 & 2 & $\mathrm{E}$ & 1 & 1 & 2 & 165 & 39 & 11 & 15.1 \\
\hline Oligodon jintakunei & $15-15-15$ & 7 & $3-4$ & 7 & PD & $\mathrm{F}$ & 1 & 1 & $\mathrm{D}$ & $1 *$ & 1 & 1 & 189 & 46 & 6 & 17.5 \\
\hline Oligodon lungshenensis & $15-15-15$ & 6 & $3-4$ & 6 & $\mathrm{E}$ & $\mathrm{F}$ & 1 & 2 & $\mathrm{D}$ & 0 & 1 & 2 & $163-179$ & $31-38$ & 8 & 20.0 \\
\hline Oligodon ornatus & $15-15-15$ & 6 & $3-4$ & 7 & E or D & $\mathrm{S}$ & $1-2$ & $1-2$ & $\mathrm{D}$ & 0 & 1 & 2 & $156-182$ & $27-44$ & $6-8$ & 15.6 \\
\hline Oligodon hamptoni & $15-15-15$ & 5 & $2-3$ & 5 & E & $\mathrm{F}$ & 1 & 2 & $\mathrm{D}$ & 0 or $1 *$ & 1 & 2 & $160-175$ & $30-32$ & $7-8$ & 12.7 \\
\hline Oligodon mcdougalli & $13-13-13$ & 7 & $3-4$ & 7 & $?$ & S & $?$ & $?$ & $\mathrm{D}$ & 0 & 1 & 2 & 200 & 39 & $?$ & $?$ \\
\hline Oligodon planiceps & $13-13-13$ & 5 & 3 & 6 & $\mathrm{E}$ & $\mathrm{S}$ & 1 & 2 & $\mathrm{D}$ & 1 & 1 & 1 & $132-145$ & $22-27$ & 10 & 9.6 \\
\hline Oligodon torquatus & $15-15-15$ & 7 & $3-4$ & 7 & $\mathrm{E}$ & $\mathrm{S}$ & 1 & 2 & $\mathrm{D}$ & 1 & 1 & 2 & $144-169$ & $25-34$ & $15-16$ & 11.1 \\
\hline Oligodon dorsalis & $15-15-13$ & 7 & $3-4$ & 7 & $\mathrm{D}$ & $\mathrm{S}$ & 1 & 1 & $\mathrm{D}$ & 1 & 1 & 2 & $162-188$ & $27-51$ & $6-10$ & $16.1-19.3$ \\
\hline Oligodon melaneus & $15-15-15$ & 7 & $3-4 / 4-5$ & 7 & PD & $\mathrm{S}$ & 1 & 2 & $\mathrm{D}$ & $1 *$ & 1 & 2 & $152-160$ & $39-40$ & 7 & $15.0-16.6$ \\
\hline Oligodon brevicauda & $15-15-15$ & 7 & $3-4$ & $?$ & $\mathrm{D}$ & $\mathrm{F}$ & 2 & 2 & $?$ & 0 & 1 & 2 & $158-173$ & $25-29$ & $7-8$ & $9.6-11.0$ \\
\hline Oligodon erythrorhachis & $15-15-15$ & 7 & $3-4$ & 8 & $\mathrm{E}$ & $\mathrm{S}$ & 1 & 2 & $\mathrm{D}$ & 0 & 1 & 2 & 154 & 46 & $7-8$ & 16.5 \\
\hline
\end{tabular}

$$
1
$$


3 (Continued).

\begin{tabular}{|c|c|c|c|c|c|}
\hline Species & Hemipenis & Dorsal pattern & Ventral pattern & Distribution & Distribution in Vietnam \\
\hline Oligodon rostralis $\mathbf{s p . ~ n o v . ~}$ & $\begin{array}{l}1 / 3 \text { forked, flounced, no } \\
\text { spines }\end{array}$ & $\begin{array}{l}\text { 14+4 large dark blotches, light } \\
\text { middorsal stripe }\end{array}$ & $\begin{array}{l}\text { cream with black } \\
\text { quadrangular spots }\end{array}$ & S Vietnam & Lam Dong \\
\hline Oligodon annamensis & $\begin{array}{l}\text { deeply forked, transverse } \\
\text { ridges and papillae }\end{array}$ & 10 light narrow crossbars & $\begin{array}{l}\text { red with dark bars or } \\
\text { quadrangular spots }\end{array}$ & S Vietnam, Cambodia & Lam Dong, Dak Lak \\
\hline Oligodon catenatus & $\begin{array}{l}\text { not forked, spinose } \\
\text { throughout }\end{array}$ & 4 longitudinal stripes & $\begin{array}{l}\text { red with black quadrangular } \\
\text { spots }\end{array}$ & $\begin{array}{l}\text { S China, E India, N Myanmar, } \\
\text { N Vietnam, Cambodia (?) }\end{array}$ & $\begin{array}{l}\text { Lao Cai, Vinh Phuc, Son } \\
\text { La }\end{array}$ \\
\hline Oligodon eberharti & $?$ & longitudinal stripes & $\begin{array}{l}\text { red with dark bars or } \\
\text { quadrangular spots }\end{array}$ & $\begin{array}{l}\text { S China, N Myanmar, N Laos, } \\
\text { N Vietnam, Cambodia (?) }\end{array}$ & $\begin{array}{l}\text { Lai Chau, Lao Cai, } \\
\text { Tuyen Quang, Cao Bang, } \\
\text { Bac Kan, Vinh Phuc, Son } \\
\text { La, Ha Tay }\end{array}$ \\
\hline Oligodon lacroixi & not forked & 4 longitudinal stripes & dark bars or spots & S China; Vietnam & Lao Cai, Phu Tho \\
\hline Oligodon inornatus & not forked & uniform pale brown & uniform, no dark bars or spots & $\begin{array}{l}\text { Cambodia, Thailand, Vietnam } \\
\text { (?) }\end{array}$ & 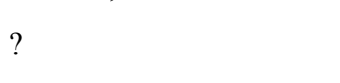 \\
\hline Oligodon kampucheaensis & deeply bifurcated & $17+3$ light narrow crossbars & $\begin{array}{l}\text { dark quadrangular spots in } \\
\text { posterior half }\end{array}$ & Cambodia & - \\
\hline Oligodon jintakunei & $?$ & $11+3$ light narrow crossbars & uniform, no dark bars or spots & S Thailand & - \\
\hline Oligodon lungshenensis & $?$ & $\begin{array}{l}4 \text { dark longitudinal stripes, } 9-12 \\
\text { brown crossbars }\end{array}$ & $\begin{array}{l}\text { orange-red with black } \\
\text { quadrangular spots }\end{array}$ & S China & - \\
\hline Oligodon ornatus & $\begin{array}{l}\text { not forked, spinose } \\
\text { throughout }\end{array}$ & $7-9+2-3$ dark crossbars & $\begin{array}{l}\text { orange-red with black } \\
\text { quadrangular spots }\end{array}$ & Taiwan & - \\
\hline Oligodon hamptoni & not forked, spinose flounces & $\begin{array}{l}\text { light vertebral and two dorsolateral } \\
\text { stripes }\end{array}$ & $\begin{array}{l}\text { red with dark bars or } \\
\text { quadrangular spots }\end{array}$ & N Myanmar & - \\
\hline Oligodon mcdougalli & $?$ & black with rusty middorsal stripe & $\begin{array}{l}\text { uniform black with light } \\
\text { mottling }\end{array}$ & Myanmar & - \\
\hline Oligodon planiceps & $\begin{array}{l}\text { not forked, spinose and } \\
\text { papillae }\end{array}$ & pale brown with dark reticulations & uniform yellow & S Myanmar & - \\
\hline Oligodon torquatus & $\begin{array}{l}\text { not forked, no spines, with } \\
\text { folds }\end{array}$ & 4 longitudinal stripes & white, black spots posteriorly & C Myanmar & - \\
\hline Oligodon dorsalis & $\begin{array}{l}1 / 3 \text { forked, flounced, basal } \\
\text { spines }\end{array}$ & $\begin{array}{l}\text { dark brown with light middorsal } \\
\text { stripe }\end{array}$ & $\begin{array}{l}\text { unfiorm orange or white with } \\
\text { black quadrangular spots }\end{array}$ & NE India, N Myanmar & - \\
\hline Oligodon melaneus & $\begin{array}{l}\text { not forked, spinose } \\
\text { throughout }\end{array}$ & blackish-brown with speckles & uniform blue-grey & NE India & - \\
\hline Oligodon brevicauda & $?$ & brown with light vertebral stripe & $\begin{array}{l}\text { whitish with black } \\
\text { quadrangular spots }\end{array}$ & S India & - \\
\hline Oligodon erythrorhachis & $?$ & $\begin{array}{l}\text { red vertebral stripe with many black } \\
\text { crossbars }\end{array}$ & $\begin{array}{l}\text { whitish with black } \\
\text { quadrangular spots }\end{array}$ & NE India & - \\
\hline
\end{tabular}

4 


\section{Figure 1}

Known distribution of Oligodon annamensis Leviton, 1953 (red) and Oligodon rostralis sp. nov. (yellow) in Indochina.

Star and dot in the center of icon denotes type locality. Localities: (1) Bidoup-Nui Ba NP, Lam Dong Province, Vietnam (type locality of Oligodon rostralis sp. nov.); (2) Bao Loc (formerly "Blao, Haut Donai"), Lam Dong Province, Vietnam (type locality of $O$. annamensis); (3) Chu Yang Sin NP, Dak Lak Province, Vietnam; (4) Phnom Samkos WS, Pursat Province, Cambodia. 


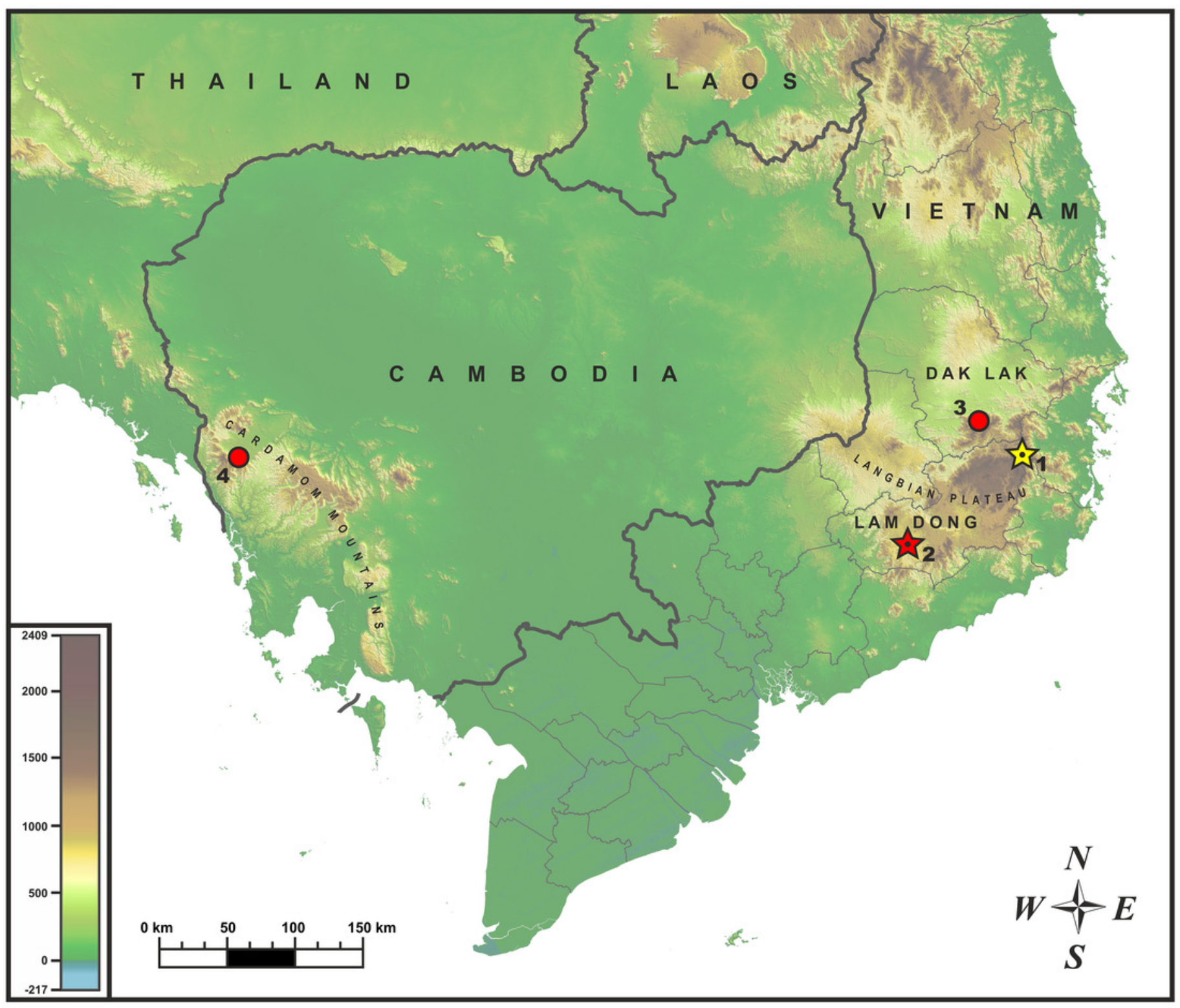




\section{Figure 2}

Bayesian inference tree of Oligodon derived from the analysis of $3131 \mathrm{bp}$ of $12 \mathrm{~S}$ rRNA, $16 S$ rRNA and cyt $b$ mitochondrial DNA gene sequences.

For voucher specimen information and GenBank accession numbers see Table 1. Numbers at tree nodes correspond to BI PP/ML BS support values, respectively; n-dash denotes no support. Outgroup taxa not shown. Colors of clades and locality numbers correspond to those in Figure 1.

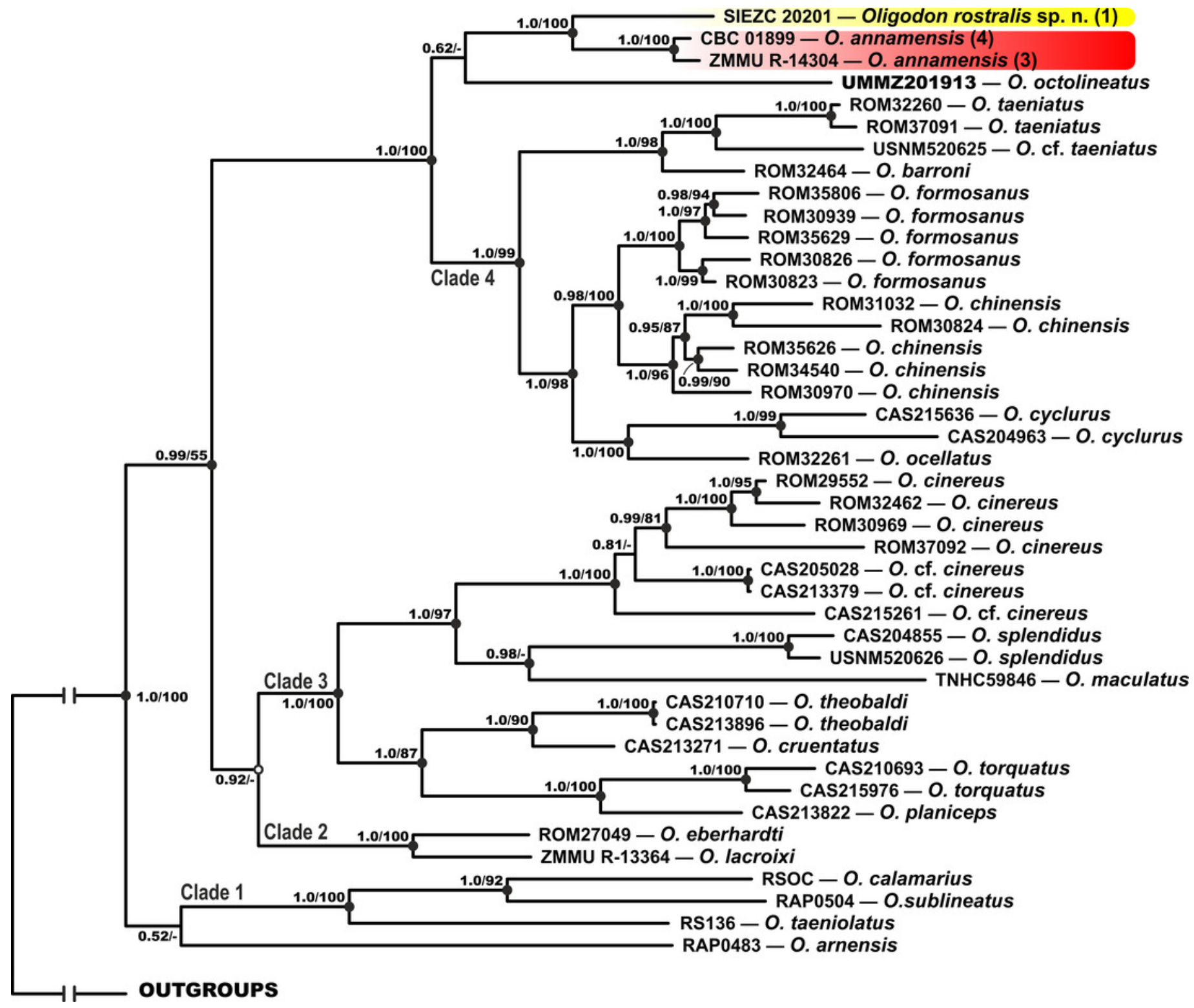


Figure 3

Holotype of Oligodon rostralis sp. nov. in preservative (SIEZC 20201, male) in dorsal (A) and in ventral $(B)$ views.

Scale bar denotes $20 \mathrm{~mm}$. Photos by Bang Van Tran. 


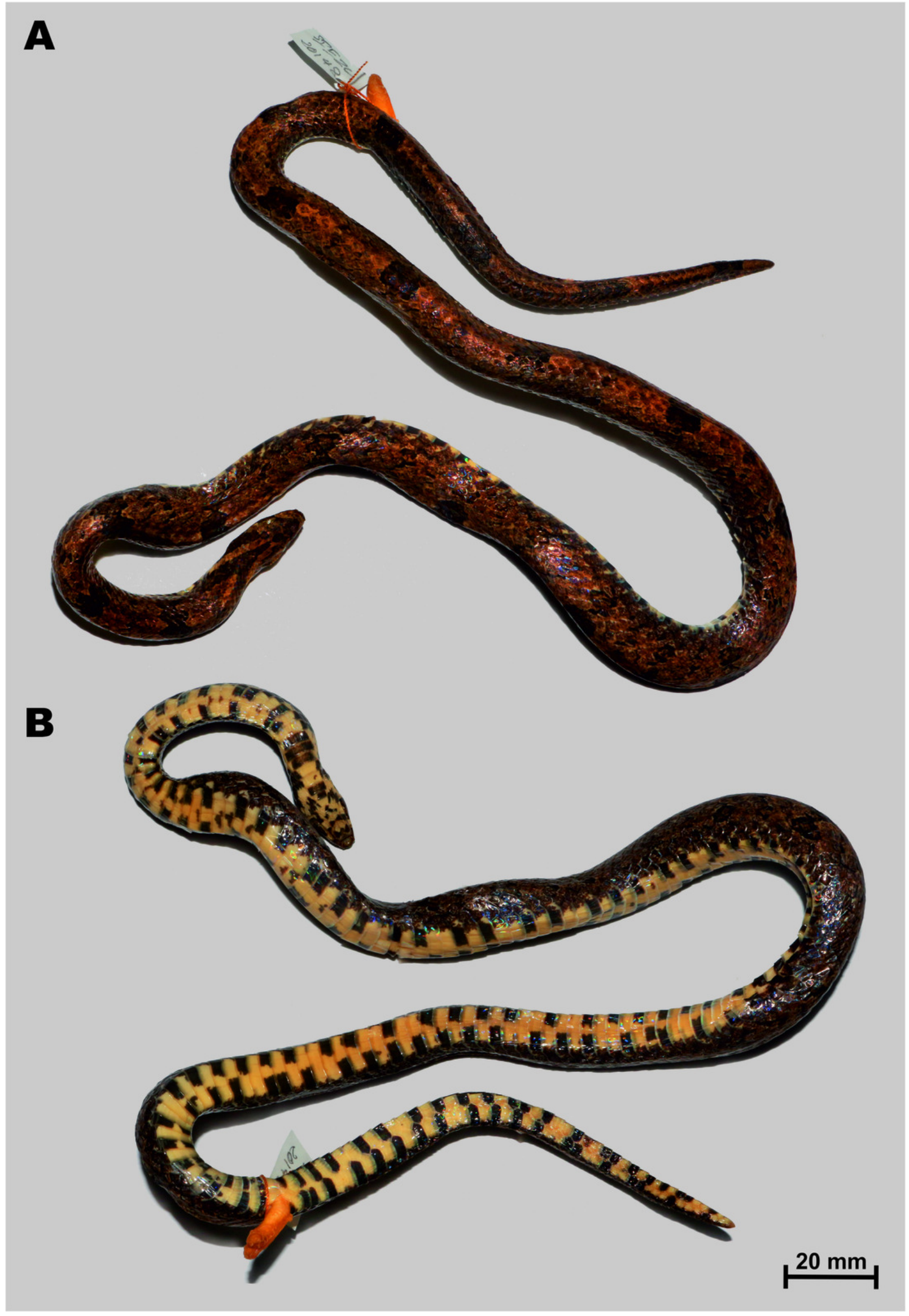




\section{Figure 4}

Drawings $(A, C, E)$ and photos $(B, D, F)$ showing head scalation of the holotype Oligodon rostralis sp. nov. in preservative (SIEZC 20201, male).

$(A, B)$ Dorsal view; $(C, D)$ lateral view; $(E, F)$ ventral view. Scale bar equals $5 \mathrm{~mm}$. Drawings and photos by Linh Hoang Nguyen.
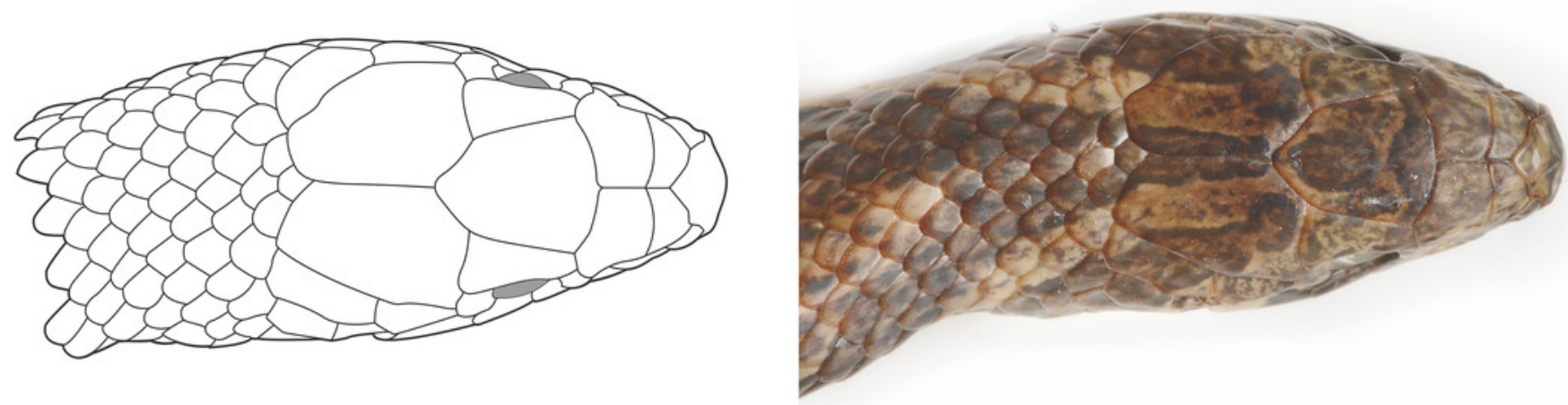

$\mathbf{A}$

B
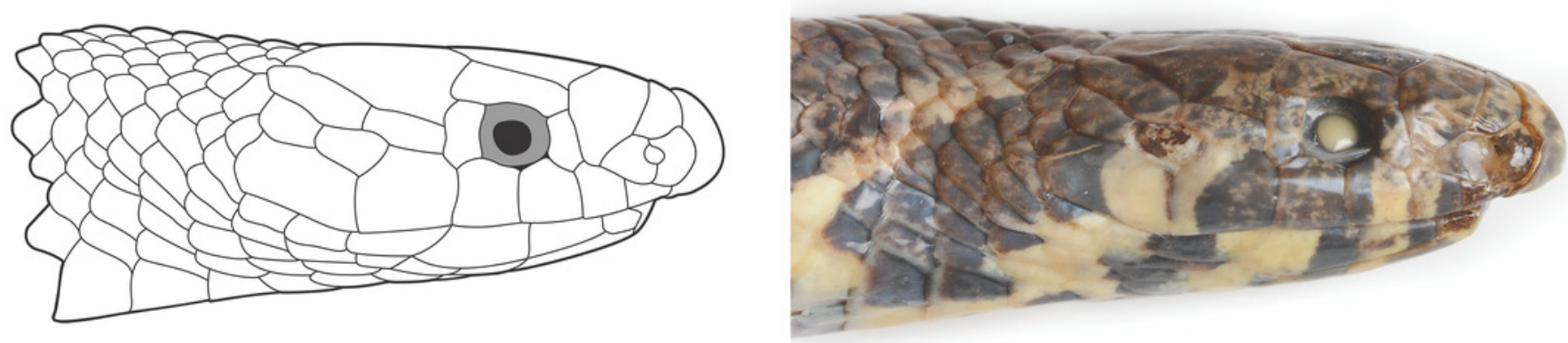

C

D
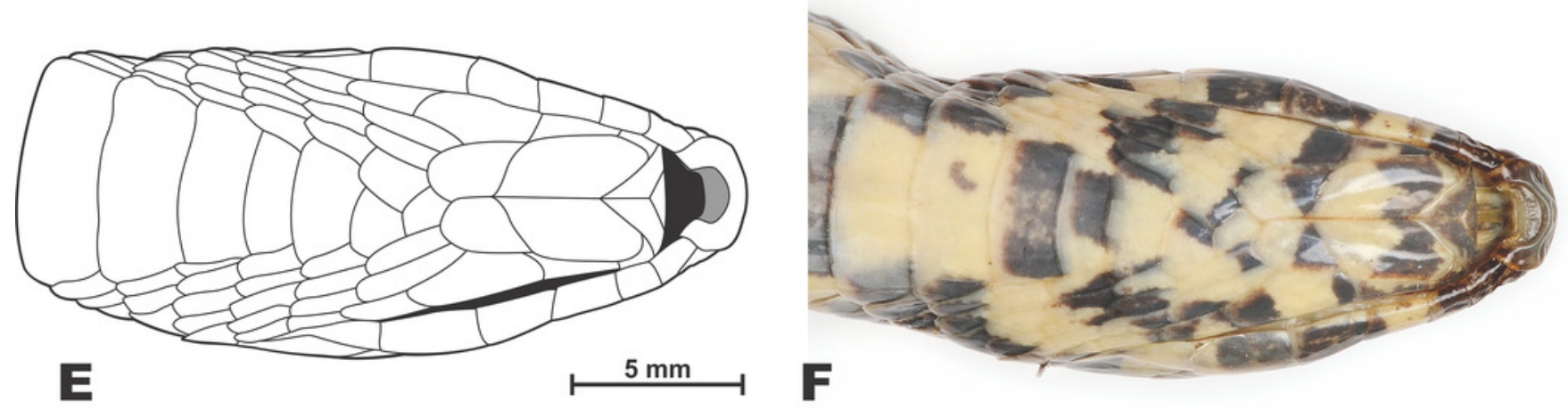


\section{Figure 5}

Hemipenial morphology of Oligodon rostralis sp. nov. holotype in preservative (SIEZC 20201, male).

$(A, C)$ - Drawings; $(B, D)$ - photos; $(A, B)$ right hemipenis in sulcal view; $(C, D)$ right hemipenis in asulcal view. Scale bar equals $2 \mathrm{~mm}$ and represents photograph of hemipenis. Photos by Bang Van Tran; drawings by Platon V. Yushchenko.

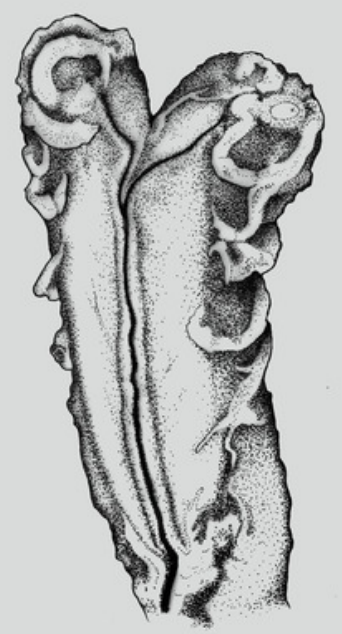

$\mathbf{A}$

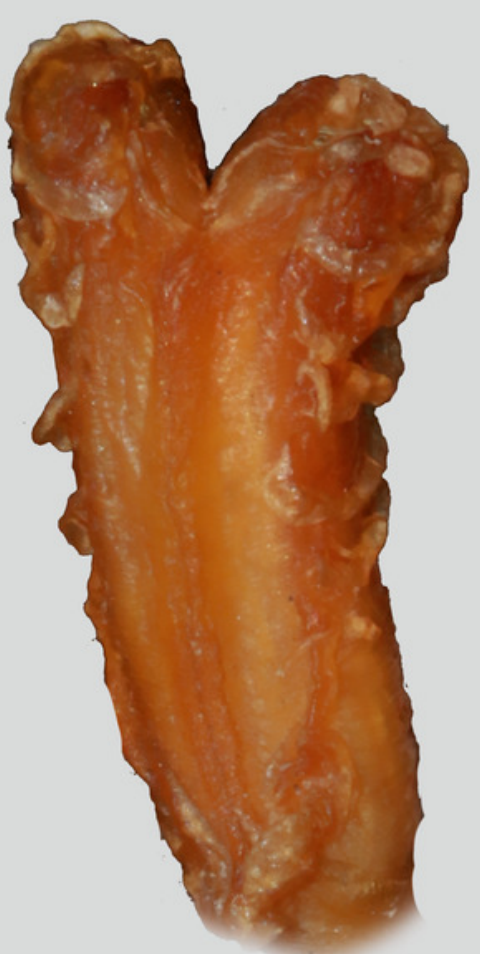

B

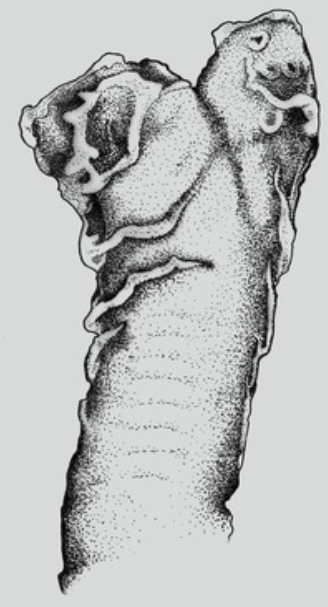

C

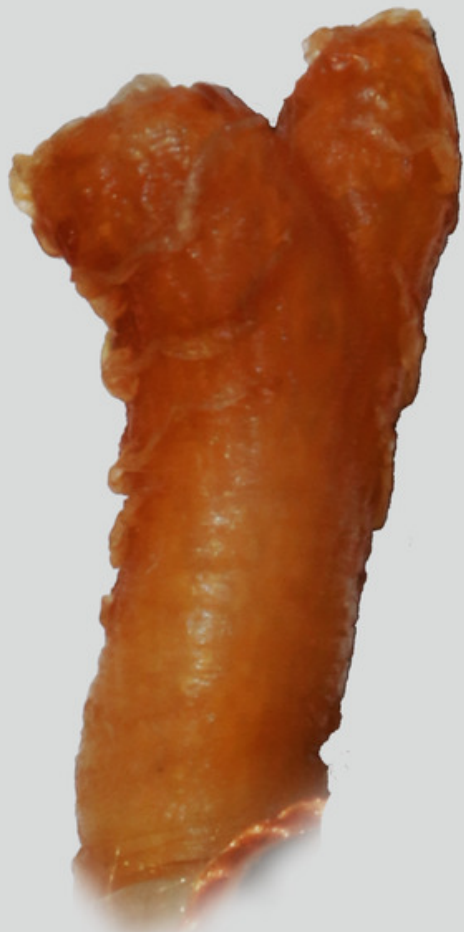

D 
Figure 6

Holotype of Oligodon rostralis sp. nov. in life in situ (SIEZC 20201, male) in dorsal (A) and in frontal (B) views.

Photos by Linh Hoang Nguyen. 

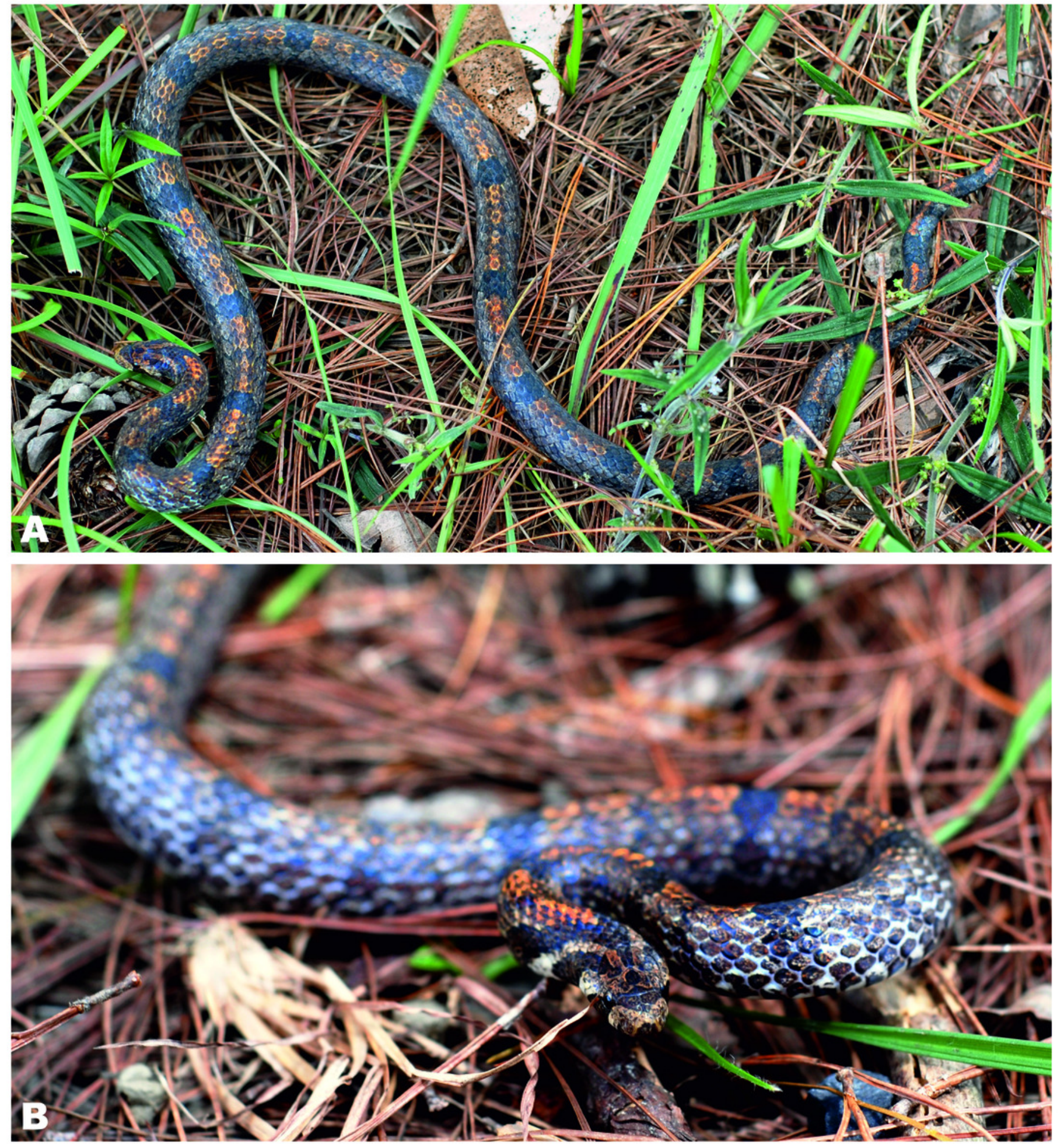


\section{Figure 7}

Natural habitat of Oligodon rostralis sp. nov. at the type locality in pine forest dominated by Pinus kesiya Royle ex Gordon in Bidoup - Nui Ba NP, Lam Dong Province, Langbian Plateau, southern Vietnam.

(A) Live ventral coloration of Oligodon rostralis sp. nov. (SIEZC 20201, male); (B) general view of the macrohabitat (elevation 1622 m a.s.l.). Photos by Linh Hoang Nguyen.
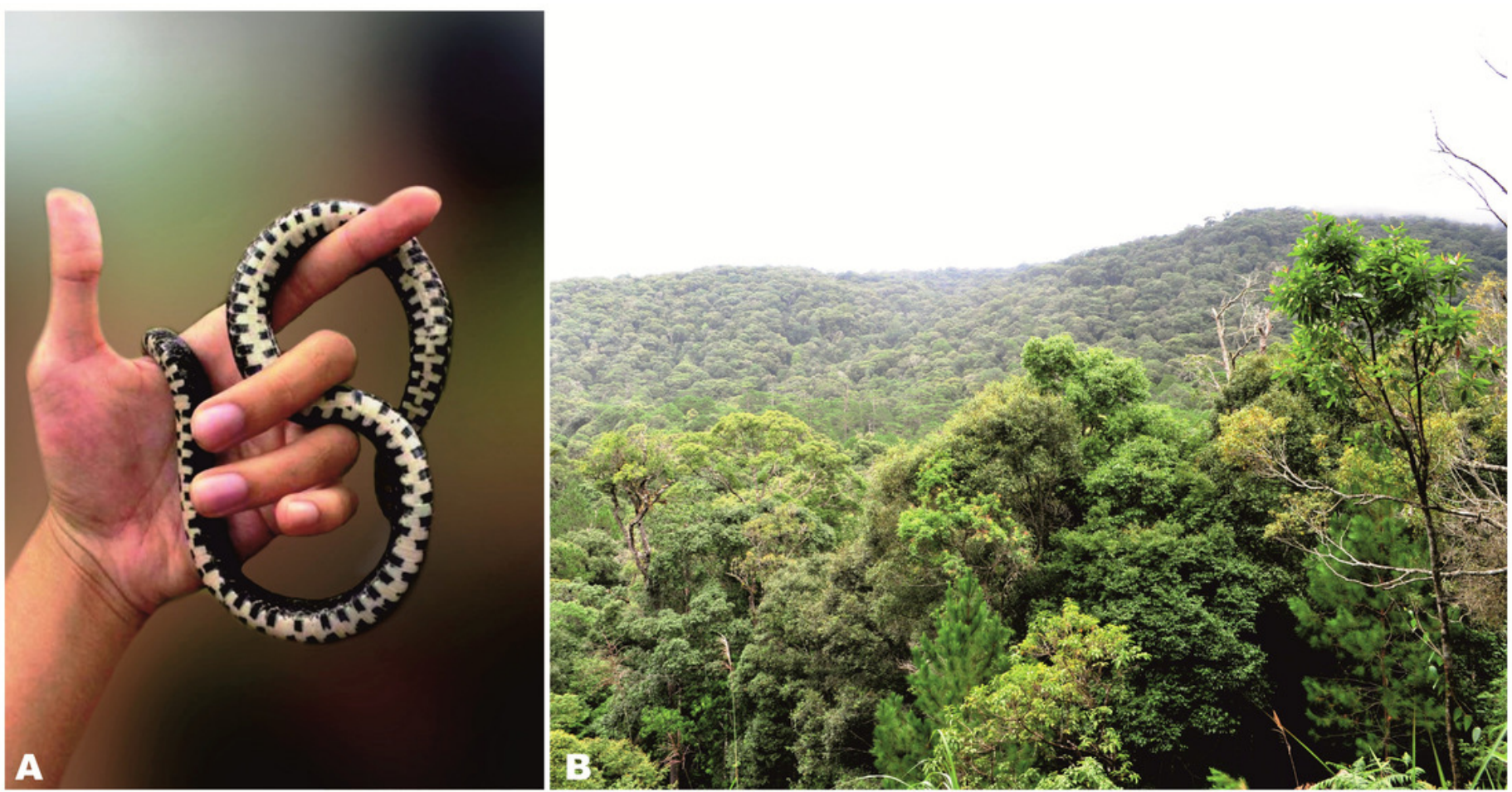
Figure 8

Holotype of Oligodon annamensis Leviton, 1953 from "Blao, Haut Donai, Station Agricole" (now Bao Loc, Lam Dong Province, southern Vietnam) in preservative (USNM 90408, female).

(A) General dorsal view; (B) general ventral view; (C) dorsal, (D) ventral, and (E) lateral head views. Photos by Justin L. Lee; courtesy of National Museum of Natural History, Smithsonian Institution. 

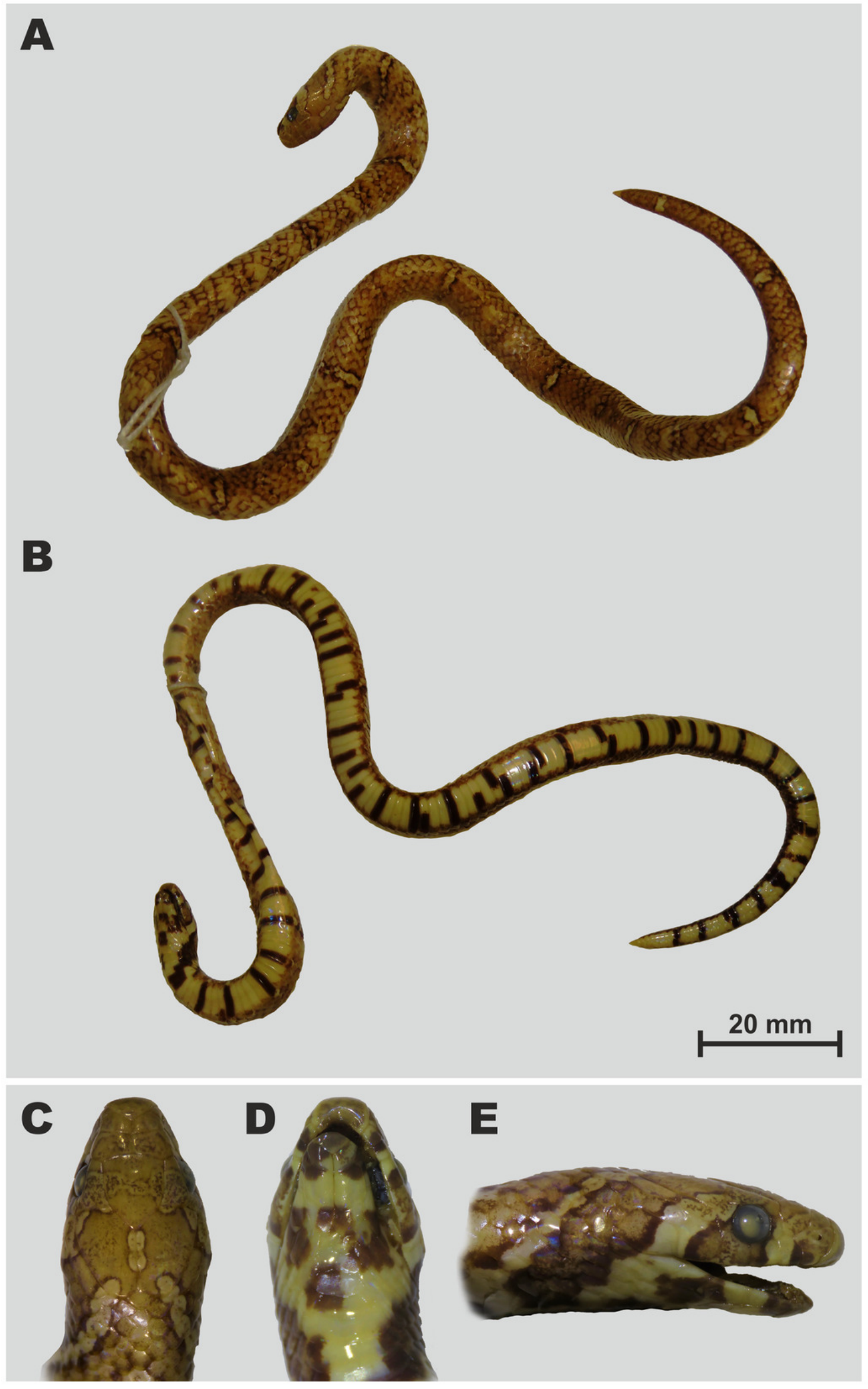

Peer) reviewing PDF | (2019:10:41846:1:1:NEW 23 Nov 2019) 


\section{Figure 9}

Specimen of Oligodon annamensis Leviton, 1953 from "Blao, Haut Donai, Station Agricole" (now Bao Loc, Lam Dong Province, southern Vietnam) in preservative (MNHN 8815 , male).

(A) Dorsal view; (B) ventral view. Photos by Patrick David.

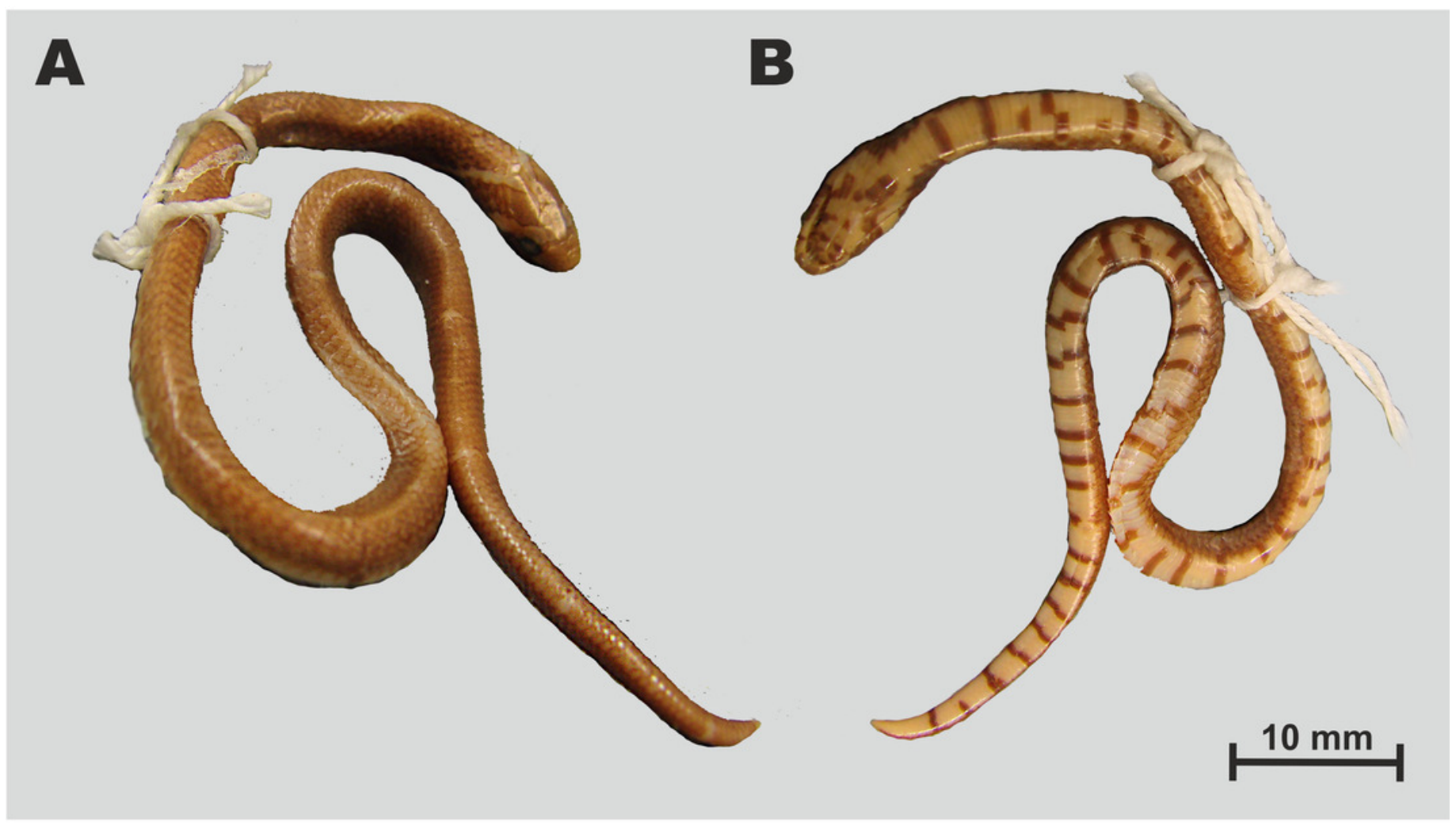


Figure 10

Specimen of Oligodon annamensis Leviton, 1953 from Chu Yang Sin NP, Dak Lak Province, southern Vietnam, in life (ZMMU R-14304, male).

(A) General dorso-lateral view; (B) general ventral view; (C) head in dorsal view; (D) head in ventral view. Photos by Nikolay A. Poyarkov. 

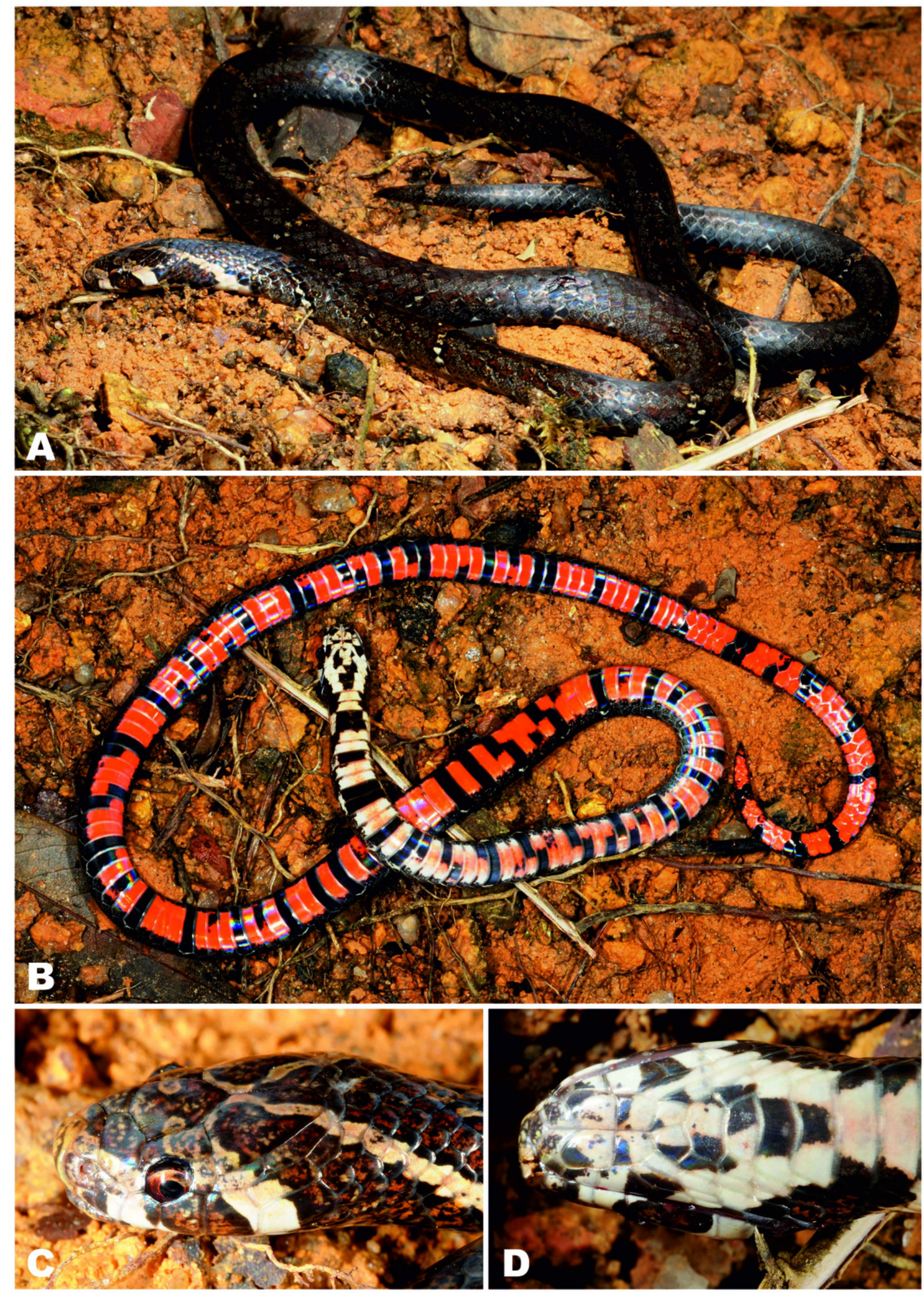
Figure 11

Specimen of Oligodon annamensis Leviton, 1953 from Phnom Samkos WS, Dak Lak Pursat, Cardamom Mountains, Cambodia, in life (CBC 01899, male).

(A) Dorsal view; (B) ventral view. Photos by Hun Seiha. 


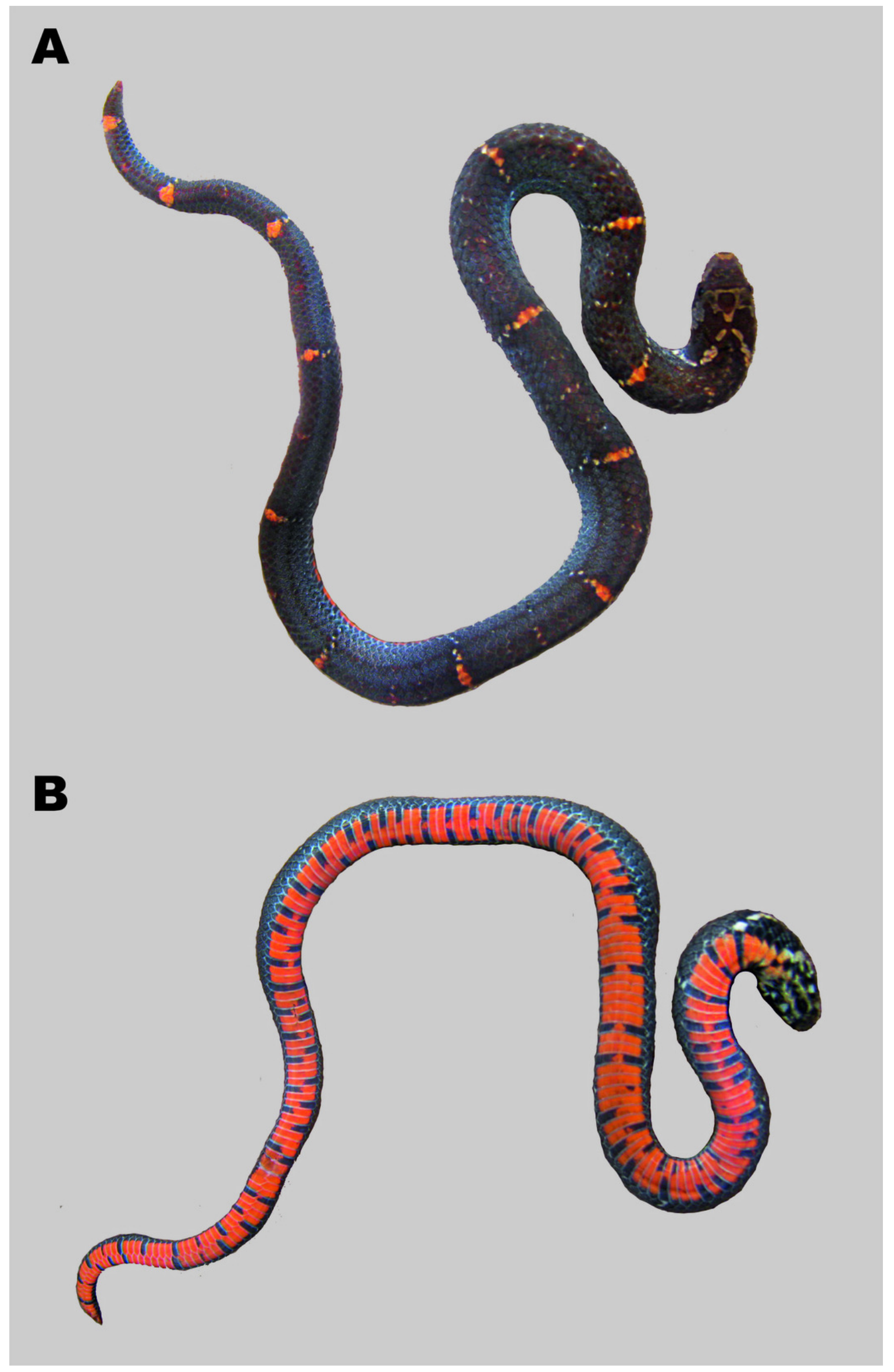

